\title{
Mass Transport Properties of Manganese Dioxide Phases for Use in Electrochemical Capacitors: Structural Effects on Solid State Diffusion
}

\author{
Madeleine F. Dupont, ${ }^{\mathrm{a}, *}$ Andrew D. Cross, ${ }^{\mathrm{a}}$ Alban Morel, ${ }^{\mathrm{b}, *}$ Mickael Drozd, \\ Anthony. F. Hollenkamp, ${ }^{c}$ and Scott W. Donne ${ }^{\mathrm{a}, * *, \mathrm{z}}$ \\ ${ }^{a}$ Discipline of Chemistry, University of Newcastle, Callaghan, NSW 2308, Australia \\ ${ }^{b}$ LGMPA, Polytech Nantes, Nantes Cedex 3 44306, France \\ ${ }^{c}$ CSIRO Division of Energy Technology, Clayton South, VIC 3169, Australia
}

\begin{abstract}
The solid state mass transport characteristics of various manganese dioxide phases has been examined with a focus on their use in electrochemical capacitors. The phases examined included $\gamma-\mathrm{MnO}_{2}$ (electrolytic manganese dioxide), $\beta-\mathrm{MnO}_{2}$ (Pyrolusite), Ramsdellite, $\delta-\mathrm{MnO}_{2}$ (Birnessite), $\alpha-\mathrm{MnO}_{2}$ (Cryptomelane) and $\lambda-\mathrm{MnO}_{2}$. Diffusion within each phase was examined using electrochemical impedance spectroscopy (EIS) and step potential electrochemical spectroscopy (SPECS). A $\sqrt{ } \mathrm{D}$ (where A is surface area and $\mathrm{D}$ is the diffusion coefficient) decreases with depth of discharge, and is also affected by the phase of manganese dioxide studied, with $\gamma-\mathrm{MnO}_{2}$ exhibiting the highest $\mathrm{A} \sqrt{ } \mathrm{D}$ value. Overall, values of $\mathrm{A} \sqrt{ } \mathrm{D}$ varied between $3 \times 10^{-8}-2 \times 10^{-10} \mathrm{~m}^{3} / \mathrm{s}^{1 / 2} / \mathrm{g}$, which is comparable with literature data. These results also provide information on the kinetics of lattice expansion and contraction which occurring during cycling. High surface area phases such as $\gamma-\mathrm{MnO}_{2}$, Ramsdellite and Cryptomelane, showed significant hysteresis in lattice contraction which is attributed to the diffusion of protons through surface domains. Low surface area phases (Pyrolusite and $\lambda-\mathrm{MnO}_{2}$ ) did not display this hysteresis, suggesting that proton diffusion occurs predominantly in the bulk of the material. No direct correlation between mass transport and specific capacitance is observed, suggesting that other material properties contribute to specific capacitance.
\end{abstract}

(C) 2013 The Electrochemical Society. [DOI: 10.1149/2.012308jes] All rights reserved.

Manuscript submitted February 18, 2013; revised manuscript received March 26, 2013. Published May 24, 2013.

Energy storage.- Currently fossil fuel combustion is the major source of global energy production. With the increasing demand for energy, the non-renewable nature of fossil fuels has necessitated the development of new energy production systems and energy storage methods. Chemical energy storage, which is utilized in devices such as batteries and supercapacitors, provides an efficient, high grade means of energy storage.

Batteries and supercapacitors are both a form of chemical energy storage. Batteries are primarily faradaic systems in that they store energy as chemical energy which is released as a result of faradaic redox processes. Capacitors are non-faradaic systems because energy is stored electrostatically as the separation of positive and negative charge at the electrode-electrolyte interface, without any charge transfer processes. ${ }^{1}$ This occurs when an electrode is charged causing the ions in the electrolyte to accumulate at the surface of the electrode to balance the charge. This region of increased ionic concentration is known as the electrical double layer.

In addition to double layer charging some materials undergo fast, highly reversible redox reactions during charging and discharging. Because these reactions are faradaic, they are not strictly capacitive, and hence they are termed pseudo-capacitive. Pseudo-capacitance contributes to the overall charge storage of the electrode, thus increasing its specific energy.

A range of materials exhibiting pseudo-capacitance have been studied as potential electrode materials for supercapacitors. Metal oxides are one of the most commonly studied classes of materials. The prototypical metal oxide exhibiting pseudo-capacitance is hydrous amorphous $\mathrm{RuO}_{2}$, which has demonstrated capacitances of up to $\sim 900 \mathrm{~F} / \mathrm{g}^{2-4}$ However, due to its high cost and environmentally damaging nature, alternative options have been investigated.

Manganese dioxide is an alternative which is relatively inexpensive, non-toxic and readily available. It has been used extensively as an electrode material in batteries due to its excellent electrochemical properties. ${ }^{5,6}$ The high capacitance of manganese dioxide can be attributed to both its high surface area, which contributes to charge storage in the electrical double layer, and the pseudo-capacitive reactions.

*Electrochemical Society Student Member.

** Electrochemical Society Active Member.

${ }^{\mathrm{z}}$ E-mail: scott.donne@newcastle.edu.au
Pseudo-capacitive reactions on manganese dioxide occur according to:

$$
\mathrm{MnO}_{2}+\mathrm{M}^{+}+\mathrm{e}^{-} \leftrightarrow \mathrm{MnOO}(\mathrm{M})
$$

where $\mathrm{M}^{+}$is a cationic species from the electrolyte, such as a proton or metal ion. ${ }^{7}$ In this process an electron from the external circuit is inserted into the electrode reducing $\mathrm{Mn}^{4+}$ to $\mathrm{Mn}^{3+}$. In order to maintain charge neutrality, a proton or metal ion from the electrolyte is intercalated into the manganese dioxide structure, forming $\mathrm{MnOO}(\mathrm{M})$. Movement of these intercalated species is driven by an activity gradient between the surface and core of the particle, with the efficacy of active material utilization being mass transport controlled and dependent upon the rate of proton diffusion through the electrode. Solid state proton diffusion occurs via particles hopping between adjacent sites i.e., electrons between $\mathrm{Mn}^{4+}$ ions and protons between $\mathrm{O}^{2-}$ ions ${ }^{8-14}$ Hence, the crystallographic structure of the material, which influences the rate of intercalated species diffusion through the structure, can have a dramatic effect on the total capacitance of the material.

Manganese dioxide structural varieties. - The crystallographic structure of manganese dioxide can vary significantly. Each different phase arises as a result of the varying arrangements in edge and corner sharing of the $\left[\mathrm{MnO}_{6}\right]$ octahedra. The result is a range of materials which can be categorized as either tunnel, layer or intergrowth structures. ${ }^{15-17}$

Tunnel structures are formed when chains of edge sharing octahedra are attached to neighboring chains by corner sharing. This arrangement forms tunnels extending along the crystallographic caxis. The number of chains on each edge determines the dimensions of the tunnel, usually expressed as the number of $\left[\mathrm{MnO}_{6}\right]$ octahedra. Pyrolusite $\left(\beta-\mathrm{MnO}_{2}\right)$ has the smallest tunnels $([1 \times 1]$ octahedra $)$, but larger tunnel structures such as Ramsdellite $([2 \times 1])$ can occur. Other tunnel structures, such as Crytpomelane $\left(\alpha-\mathrm{MnO}_{2}\right)$, which contains $[2 \times 2]$ tunnels, are large enough to incorporate cations, such as $\mathrm{K}^{+}$, into the structure.

Layered structures of manganese dioxide differ somewhat from the tunnel structures, most notably the material consists of discrete layers rather than a continuous tunnel structure. Most of these layered structures contain interlayer cations which act to stabilize the structure. Birnessite is an example of a layered structure - it consists of layers of 
edge-sharing octahedra with interlayer cations such as $\mathrm{Na}^{2+}$ or $\mathrm{Ca}^{2+}$ and water molecules.

$\lambda-\mathrm{MnO}_{2}$ is a spinel structure best described as a cubic close packed arrangement of oxygen ions with four octahedral and eight tetrahedral vacancies per formula unit, where half of the octahedral vacancies are filled by $\mathrm{Mn}^{4+}$ ions. ${ }^{18}$ This structure forms a three-dimensional network of edge-sharing $\left[\mathrm{MnO}_{6}\right]$ octahedra.

Another commonly studied phase of manganese dioxide is the intergrowth structure $\gamma-\mathrm{MnO}_{2}$. Intergrowth structures are some of the most electrochemically significant forms of manganese dioxide due to their complexity, which can include cation vacancies, defects and structural water, all of which have been found to affect the electrochemical behavior of the material.

This work.- Manganese dioxide has been studied extensively in alkaline electrolytes due to its widespread use as a battery electrode material. However, there is no published literature on its mass transport characteristics in neutral electrolytes, such as are used in supercapacitors. In this work, different phases of manganese dioxide including pyrolusite, ramsdellite, cryptomelane, birnessite, $\lambda-\mathrm{MnO}_{2}$ and $\gamma-\mathrm{MnO}_{2}$, were studied in a neutral electrolyte to examine how the crystallographic structure affects the solid state diffusion of protons. This will provide important insight into the charge storage mechanism of various manganese dioxide phases used in supercapacitor electrodes. Most importantly, it should identify any correlation between structure and performance.

\section{Experimental}

Material synthesis. - Pyrolusite $\left(\beta-\mathrm{MnO}_{2}\right)$. - The pyrolusite phase was synthesized via thermal treatment of electrolytic manganese dioxide (EMD; $\gamma-\mathrm{MnO}_{2}$ ) from Delta EMD Australia. Specifically, a $10 \mathrm{~g}$ sample of EMD was heated in air in an alumina crucible at $350^{\circ} \mathrm{C}$ for 24 hours. During this process structural water and cation vacancies were annealed from the $\gamma-\mathrm{MnO}_{2}$ structure, at the same time as $\mathrm{Mn}^{4+}$ ion transport to form the $[1 \times 1]$ pyrolusite tunnels. ${ }^{19}$

Ramsdellite.- The precursor for this synthesis was $\mathrm{Mn}_{2} \mathrm{O}_{3}$ that had been prepared by heat treating $\gamma-\mathrm{MnO}_{2}$ (EMD) in air at $550^{\circ} \mathrm{C}$ for 24 hours. The ramsdellite phase was then prepared by acid disproportionation of the $\mathrm{Mn}_{2} \mathrm{O}_{3}$ in $0.1 \mathrm{M} \mathrm{H}_{2} \mathrm{SO}_{4}$ at ambient temperatures over a period of 7 days; ${ }^{20}$ i.e.,

$$
\mathrm{Mn}_{2} \mathrm{O}_{3}+2 \mathrm{H}^{+} \rightarrow \mathrm{Mn}^{2+}+(\mathrm{R}) \mathrm{MnO}_{2}+\mathrm{H}_{2} \mathrm{O}
$$

After this reaction time the product was filtered and washed thoroughly with Milli-Q ultra-pure water (resistivity, $\rho>18.2 \mathrm{M} \Omega \mathrm{cm}$ ).

Cryptomelane $\left(\mathrm{K}^{+}\right.$-modified $\left.\alpha-\mathrm{MnO}_{2}\right)$. - The cryptomelane phase was prepared by decomposing $1.82 \mathrm{~g}$ of $\mathrm{KMnO}_{4}$ dissolved in $100 \mathrm{~mL}$ of $1 \mathrm{M} \mathrm{H}_{2} \mathrm{SO}_{4}$ at $60^{\circ} \mathrm{C}$. The $\mathrm{MnO}_{4}{ }^{-}$ion is thermodynamically unstable in aqueous solution, ${ }^{21}$ decomposing by reaction with the solvent water; i.e.,

$$
\begin{aligned}
& \text { Reduction : } \mathrm{MnO}_{4}^{-}+4 \mathrm{H}^{+}+3 \mathrm{e}^{-} \rightarrow(\alpha) \mathrm{MnO}_{2}+2 \mathrm{H}_{2} \mathrm{O} \\
& \text { Oxidation : } 2 \mathrm{H}_{2} \mathrm{O} \rightarrow \mathrm{O}_{2}+4 \mathrm{H}^{+}+4 \mathrm{e}^{-} \\
& \text {Overall : } 4 \mathrm{MnO}_{4}^{-}+4 \mathrm{H}^{+} \rightarrow 4(\alpha) \mathrm{MnO}_{2}+2 \mathrm{H}_{2} \mathrm{O}+3 \mathrm{O}_{2}
\end{aligned}
$$

The experimental conditions used here, together with the templating effect of the $\mathrm{K}^{+}$ions, are essentially what dictates the resultant manganese dioxide phase produced. When the reaction was complete, the product was then filtered, washed thoroughly with Milli-Q water, and then dried in air at $60^{\circ} \mathrm{C}$.

Birnessite $\left(\mathrm{K}^{+}\right.$-modified $\delta$ - $\left.\mathrm{MnO}_{2}\right)$.- Birnessite was produced as a result of the stoichiometric reaction between solutions of $0.1 \mathrm{M}$ $\mathrm{KMnO}_{4}$ and $0.1 \mathrm{M} \mathrm{MnSO}_{4}$ (2:3 volume ratio) in an aqueous media automatically $\mathrm{pH}$ adjusted via a Metrohm 775 Dosimat with $\mathrm{pH}$ feed- back loop, to 9 by the addition of a dilute $0.01 \mathrm{M} \mathrm{KOH}$ solution; ${ }^{22}$ i.e.,

$$
\begin{aligned}
& \text { Reduction : } \mathrm{MnO}_{4}^{-}+4 \mathrm{H}^{+}+3 \mathrm{e}^{-} \rightarrow(\delta) \mathrm{MnO}_{2}+2 \mathrm{H}_{2} \mathrm{O} \\
& \text { Oxidation : } \mathrm{Mn}^{2+}+2 \mathrm{H}_{2} \mathrm{O} \rightarrow \mathrm{MnO}_{2}+4 \mathrm{H}^{+}+2 \mathrm{e}^{-} \\
& \text {Overall : } 2 \mathrm{MnO}_{4}^{-}+3 \mathrm{Mn}^{2+}+2 \mathrm{H}_{2} \mathrm{O} \rightarrow 5(\delta) \mathrm{MnO}_{2}+4 \mathrm{H}^{+}
\end{aligned}
$$

As with the synthesis of cryptomelane, the experimental conditions are what dictate the nature of the phase produced. When reaction was complete, the product was filtered, washed thoroughly with Milli-Q water, and then dried in air at $60^{\circ} \mathrm{C}$.

$\lambda-\mathrm{MnO}_{2}$ - - The synthesis of $\lambda-\mathrm{MnO}_{2}$ is a two step process involving firstly the synthesis of spinel $\mathrm{LiMn}_{2} \mathrm{O}_{4}$, followed by extraction of the $\mathrm{Li}^{+}$ions from this phase. $\mathrm{LiMn}_{2} \mathrm{O}_{4}$ was prepared by grinding together using a mortar and pestle stoichiometric quantities (1:1) of $\mathrm{LiOH}$ and $\mathrm{Mn}_{2} \mathrm{O}_{3}$, followed by heat-treatment in air at $800^{\circ} \mathrm{C}$ for 48 hours. The product was then allowed to cool naturally in the furnace, removed and then re-ground a second time before heat-treatment again at $800^{\circ} \mathrm{C}$ in air for 24 hours. The product $\mathrm{LiMn}_{2} \mathrm{O}_{4}$ was then suspended in Milli-Q water at ambient temperature and $0.1 \mathrm{M} \mathrm{H}_{2} \mathrm{SO}_{4}$ was added until $\mathrm{pH} \approx 2$ was obtained. The suspension was filtered, washed thoroughly with Milli-Q water and then dried in air at $60^{\circ} \mathrm{C}$. This method has previously been employed by Hunter. ${ }^{18}$

Material characterization.- The material was characterized by $\mathrm{X}$-ray diffraction using a Philips 1710 diffractometer equipped with a $\mathrm{Cu} \mathrm{K} \alpha$ radiation source $(\lambda=1.5418 \AA$ ) operating at $40 \mathrm{kV}$ and $30 \mathrm{~mA}$. The scan range was from $10-90^{\circ} 2 \theta$ with a step size of $0.1^{\circ}$ and a count time of $2.5 \mathrm{~s}$.

The surface area and porosity of each phase was also determined using a Micromeritics ASAP2020 Gas Adsorption and Porosity analyser. Samples were degassed under vacuum at $110^{\circ} \mathrm{C}$ for 2 hours to primarily remove surface water. $\mathrm{A} \mathrm{N}_{2}$ adsorption isotherm (at $77 \mathrm{~K}$ ) was then measured on each sample covering the partial pressure $\left(\mathrm{P} / \mathrm{P}_{\mathrm{o}}\right)$ range $10^{-7}-1$. The specific surface area was then determined using the linearized BET isotherm, ${ }^{23}$ while sample porosity was determined using the DFT Plus V2.0 software package.

The average manganese oxidation state for each of the samples, as reflected by the value of $\mathrm{x}$ in $\mathrm{MnO}_{\mathrm{x}}$, was determined using a two stage, single vessel potentiometric titration based on the method proposed originally by Vetter and Jaeger. ${ }^{24}$ The method involved dissolving $\sim 100 \mathrm{mg}$ of each sample in a $25.00 \mathrm{~mL}$ aliquot of $0.25 \mathrm{M} \mathrm{FeSO}_{4}$ $+10 \% \mathrm{H}_{2} \mathrm{SO}_{4}$; i.e.,

$\mathrm{MnO}_{\mathrm{x}}+(2 \mathrm{x}-2) \mathrm{Fe}^{2+}+(2 \mathrm{x}) \mathrm{H}^{+} \rightarrow \mathrm{Mn}^{2+}+(2 \mathrm{x}-2) \mathrm{Fe}^{3+}+\mathrm{xH}_{2} \mathrm{O}$

The solution was then made up to approximately $300 \mathrm{~mL}$ using Milli-Q ultrapure water, and then clean SCE and Pt wire electrodes (reference and sensing electrodes, respectively) were submerged into the solution, which was then titrated with $0.1 \mathrm{M} \mathrm{KMnO}_{4}$ to find the first potentiometric end point $\left(\mathrm{V}_{1}\right)$ corresponding to a back titration of remaining $\mathrm{Fe}^{2+}$ in the solution; i.e.,

$$
\mathrm{MnO}_{4}^{-}+5 \mathrm{Fe}^{2+}+8 \mathrm{H}^{+} \rightarrow \mathrm{Mn}^{2+}+5 \mathrm{Fe}^{3+}+4 \mathrm{H}_{2} \mathrm{O}
$$

The $\mathrm{pH}$ of the solution was then raised to 6-7 by dissolution of a suitable amount of tetrasodium pyrophosphate $\left(\mathrm{Na}_{4} \mathrm{P}_{2} \mathrm{O}_{7} \cdot 10 \mathrm{H}_{2} \mathrm{O}\right)$. A second potentiometric titration was then performed using the same $0.1 \mathrm{M} \mathrm{KMnO}_{4}$ solution $\left(\mathrm{V}_{2}\right)$, this time to determine the total manganese content of the solution; i.e.,

$\mathrm{MnO}_{4}^{-}+4 \mathrm{Mn}^{2+}+8 \mathrm{H}^{+}+15 \mathrm{H}_{2} \mathrm{P}_{2} \mathrm{O}_{7}^{2-} \rightarrow 5 \mathrm{Mn}\left(\mathrm{H}_{2} \mathrm{P}_{2} \mathrm{O}_{7}\right)_{3}^{3-}+4 \mathrm{H}_{2} \mathrm{O}$

The value of $\mathrm{x}$ in $\mathrm{MnO}_{\mathrm{x}}$ was then calculated using

$$
\mathrm{x}=1+\frac{5\left(\mathrm{~V}_{0}-\mathrm{V}_{1}\right)}{2\left(4 \mathrm{~V}_{2}-\mathrm{V}_{1}\right)}
$$

where $\mathrm{V}_{0}$ is the volume of the same $0.1 \mathrm{M} \mathrm{KMnO}_{4}$ solution used to reach the end point in the blank titration. 
Electrochemical characterization.—Electrode Ink Preparation.Here the working electrode was prepared by mixing $0.05 \mathrm{~g}$ of powdered manganese dioxide sample with $0.50 \mathrm{~g}$ Mura LX-10-B conductive carbon black in a mortar and pestle to form a homogenous mixture ( $\sim 5$ min mixing). This ratio of manganese dioxide to carbon black was chosen so as to focus only on the properties and performance of the manganese dioxide, not that of the electrode as a whole such as when lower carbon contents are used. These dry components were then transferred to a $50 \mathrm{~mL}$ glass bottle, at which point polytetraflouroethylene (PTFE) (30 wt $\%$ in water) was added as a binder at a concentration of $\sim 20 \mathrm{wt} \%$, followed by mixing in the presence of $25 \mathrm{~mL}$ of distilled water. This suspension was then ultrasonicated for $30 \mathrm{~min}$ to disperse all solid materials before being ready for use in electrode and cell construction. This method was also used to prepare the counter electrode ink. In this case the mixture consisted of $5.00 \mathrm{~g}$ of Cabot Vulcan XC72R Carbon Black with 20\% PTFE in $25 \mathrm{~mL}$ of water.

Cell construction.-The electrode was prepared by pipetting $0.200 \mathrm{~mL}$ of the electrode ink, using a Volac precision pipette, onto a titanium metal substrate (titanium foil, $99.7 \%$, thickness $0.25 \mathrm{~mm}$; Sigma Aldrich) that had been polished using 800 grit emery paper and washed with ethanol to remove particulate matter. $0.200 \mathrm{~mL}$ of the counter electrode ink was similarly deposited onto another prepared titanium sheet. The electrodes were allowed to dry in air at ambient temperature for 24 hours, leaving a thin film of the $\mathrm{MnO}_{2}$ /carbon black mixture.

The manganese dioxide and carbon black containing electrodes were then sandwiched together between two Perspex plates, separated by two sheets of separator paper, as shown in Figure 1. The plates were screwed together to maintain electrode contact, and to ensure consistent pressure the nuts were tightened to $75 \mathrm{cN} . \mathrm{m}$. This cell configuration was used for all electrochemical experiments including the combination of electrochemical impedance spectroscopy (EIS) and step potential electrochemical spectroscopy (SPECS), and cyclic voltammetry. It was used in conjunction with a saturated calomel reference electrode (SCE) to create a three-electrode cell. The cell was connected to the potentiostat by attaching alligator clips to each titanium plate as the working (manganese dioxide) and counter (activated carbon) electrodes, and the entire cell was immersed in a large, shallow beaker of the electrolyte.

Combined SPECS and EIS Experiments.-The combined SPECS EIS experiments were conducted using the combination of a Solartron 1254 Frequency Response Analyser and a Solartron 1287 Electro-

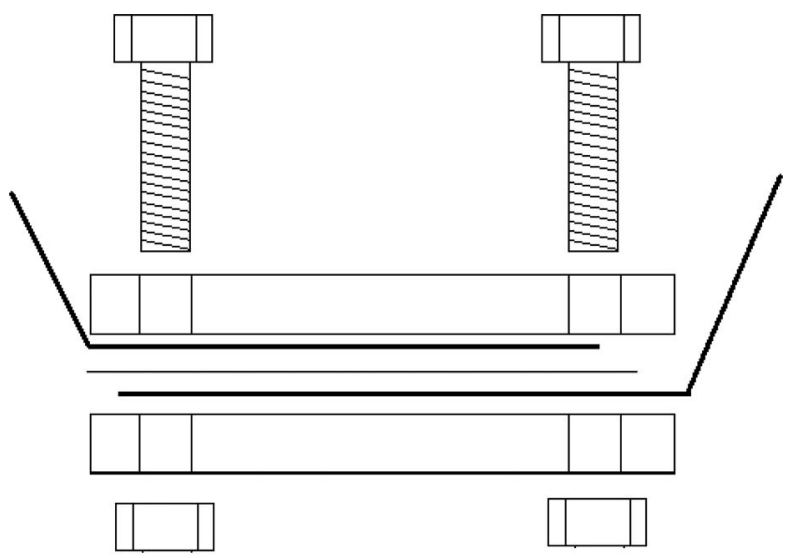

L chemical Interface controlled by ZPlot software. The manganese dioxide working electrode was allowed to equilibrate at its open circuit potential (OCP) for 10 minutes before commencing the experiment. After this time period an EIS experiment was conducted using a $10 \mathrm{mV}$ RMS ac excitation signal over the frequency range from $20 \mathrm{kHz}$ down to $0.1 \mathrm{~Hz}$. When this EIS experiment had been completed the potential was then stepped $25 \mathrm{mV}$ anodically, where the electrode was again allowed to equilibrate for another 10 minutes. It was noted that the working electrode current had effectively returned to $\sim 0 \mathrm{~mA}$ after this time. At this point another EIS experiment was conducted. This process was repeated until an upper potential of $0.8 \mathrm{~V}$ had been reached, then cathodically until $0.0 \mathrm{~V}$, and then anodically again back up to $0.8 \mathrm{~V}$.

Cyclic Voltammetry.-Cyclic voltammetry experiments were carried out on identical cells using a Princeton Applied Research VMP multichannel potentiostat/galvanostat. Here the cell was allowed to equilibrate at the OCP 10 minutes, after which the cell was cycled between $0.0-0.8 \mathrm{~V}$ for at least 50 cycles.

\section{Results and Discussion}

Material characterization.-XRD Data.- XRD patterns of the synthesized samples are shown in Figure 2, together with a standard XRD pattern for that phase from the ICSD database. ${ }^{25-30}$ The peaks in the patterns for each sample were indexed with their Miller indexes, and hence the lattice parameters were calculated, the results for which

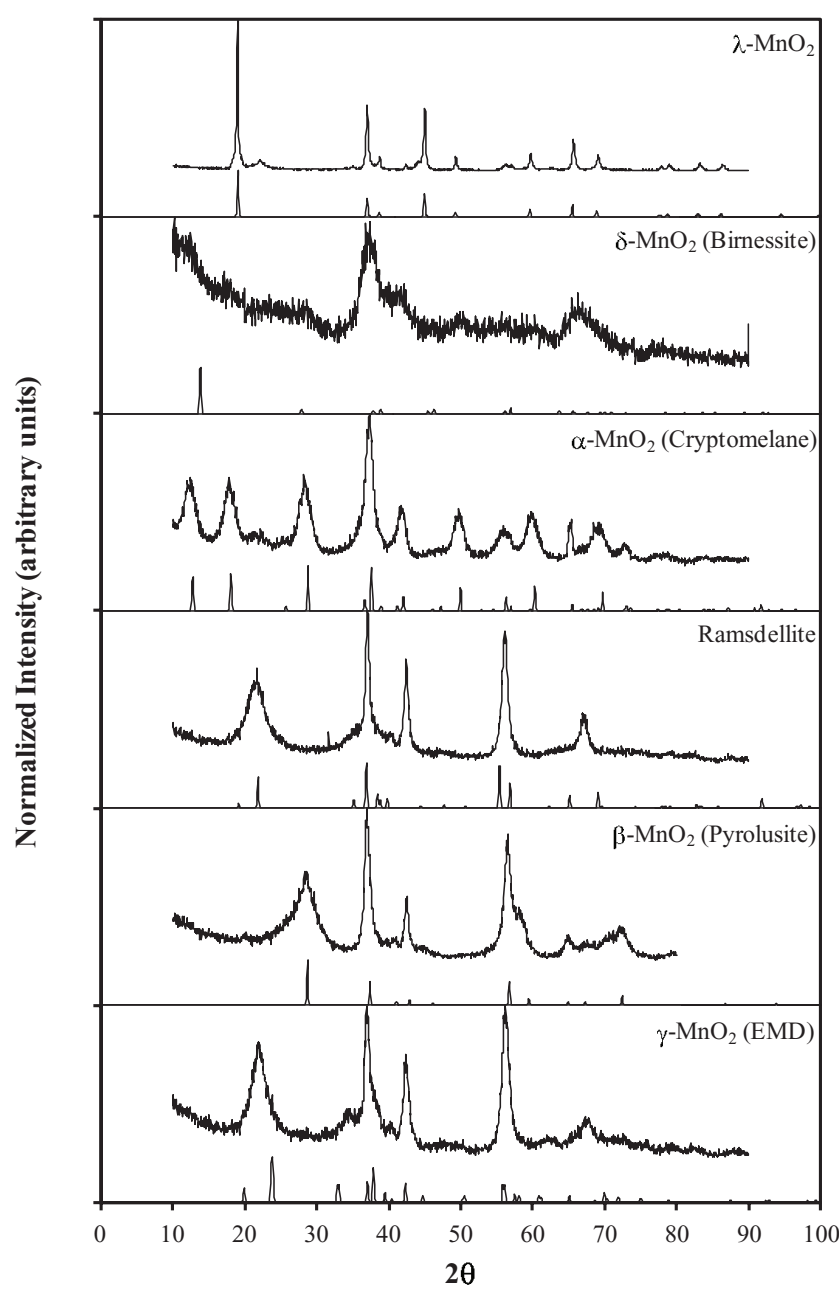

Figure 2. Experimental and literature (ICSD database) patterns for each of the manganese dioxide phases examined in this study.

Figure 1. Schematic of the electrochemical cell. 
Table I. Lattice parameters, average crystallite size and BET surface area for each phase of manganese dioxide considered.

\begin{tabular}{|c|c|c|c|c|c|c|c|c|}
\hline \multirow[b]{2}{*}{ Phase } & \multirow[b]{2}{*}{ Unit Cell } & \multicolumn{3}{|c|}{ Dimensions $(\AA)$} & \multirow{2}{*}{$\begin{array}{c}\text { Average } \\
\text { Crystal Size }(\mathrm{nm})\end{array}$} & \multirow[b]{2}{*}{$\mathrm{x}$ in $\mathrm{MnOx}$} & \multirow{2}{*}{$\begin{array}{l}\text { BET Surface } \\
\text { Area }\left(\mathrm{m}^{2} / \mathrm{g}\right)\end{array}$} & \multirow{2}{*}{$\begin{array}{c}\text { Specific Capacitance } \\
(\mathrm{F} / \mathrm{g})\end{array}$} \\
\hline & & $\mathrm{a}_{0}$ & $\mathrm{~b}_{0}$ & $\mathrm{c}_{0}$ & & & & \\
\hline$\gamma-\mathrm{MnO}_{2}$ & Orthorhombic & 4.50 & 9.56 & 2.81 & 14 & 1.965 & 26.8 & 113 \\
\hline Pyrolusite & Tetragonal & 4.44 & & 2.88 & 45 & 1.958 & 18.6 & 94 \\
\hline Birnessite & Hexagonal & 2.23 & & 7.42 & 7 & 1.940 & 87.1 & 88 \\
\hline Cryptomelane & Tetragonal & 9.82 & & 2.86 & 10 & 1.904 & 123.3 & 132 \\
\hline Ramsdellite & Orthorhombic & 9.33 & 4.51 & 2.80 & 20 & 1.968 & 23.2 & 81 \\
\hline$\lambda-\mathrm{MnO}_{2}$ & Cubic & 8.07 & & & 46 & 1.987 & 10.8 & 88 \\
\hline
\end{tabular}

are listed in Table I. All of the phases have lattice parameters in agreement with those reported in the literature.

The average crystallite size of each material was determined using the Scherrer equation; ${ }^{31}$ i.e.,

$$
\mathrm{T}=\frac{\mathrm{K} \lambda}{\beta_{\mathrm{s}} \cos (\theta)}
$$

where $\mathrm{T}$ is the average thickness of a crystal in a direction normal to the diffracting plane $(\AA), K$ is a shape factor constant $(0.9), \lambda$ is the wavelength of radiation $(1.5418 \AA), \beta_{\mathrm{s}}$ is the peak broadening (peak width at half height) due to crystallite size (in radians), and $\theta$ is the diffraction angle (radians) of the peak being considered. The peak broadening due to crystallite size $\left(\beta_{\mathrm{s}}\right)$ was determined from the Warren equation; ${ }^{31}$ i.e.,

$$
\beta_{\mathrm{s}}^{2}=\beta_{\mathrm{obs}}^{2}-\beta_{\mathrm{inst}}^{2}
$$

where $\beta_{\text {obs }}$ is the measured peak width at half height and $\beta_{\text {inst }}$ is the contribution to peak broadening from instrument effects. $\beta_{\text {inst }}$ in this case was determined from the powder diffraction pattern of crystalline $\mathrm{LaB}_{6}$. Using this approach the crystallite size for each sample, as taken from the average crystallite size from each peak in the diffraction pattern, was determined and is listed in Table I. From this data it is apparent that the thermally prepared materials $\left(\beta\right.$ - and $\left.\lambda-\mathrm{MnO}_{2}\right)$ have considerably higher crystallite sizes, most likely due to the higher temperatures enabling crystal growth as a result of enhance manganese ion mobility in the solid state. Conversely, those species made by chemical precipitation; e.g., birnessite and cryptomelane) have very small crystallite sizes, apparently due to crystal nucleation being the preferred process, rather than growth, under the conditions for which these samples were prepared. The crystallite size for $\gamma-\mathrm{MnO}_{2}$ is also relatively small, but nonetheless is typical for that of an EMD, ${ }^{32}$ and reflects the rather rapid deposition conditions used during the electrolysis process. The mild kinetic conditions used to prepare ramsdellite have apparently resulted in some crystallite growth for this material. Specific Surface Area and Porosity.-Specific surface area data for each of the phases examined in this study, as determined via $\mathrm{N}_{2}$ gas adsorption and the use of the linearized BET isotherm, is also shown in Table I. Here the BET surface area ranges from $123.3 \mathrm{~m}^{2} / \mathrm{g}$ for the cryptomelane sample, down to $10.8 \mathrm{~m}^{2} / \mathrm{g}$ for the $\lambda-\mathrm{MnO}_{2}$ sample. What is apparent from this data is that there is an inverse relationship between crystallite size and surface area, as demonstrated in Figure 3. This sort of behavior was to be expected, as is also demonstrated in Figure 3. The theoretical data set here was calculated by assuming that each particle was spherical and non-porous, and that it was individually dispersed within the sample. By then calculating for each particle (in sequence) the volume, mass (via the density, which was assumed to be $4.0 \mathrm{~g} / \mathrm{cm}^{3}$ ), and surface area, and then combining it with the number of particles per gram, the theoretical surface area was determined. As can be seen in Figure 3, the shape of the fitted and theoretical curves are very similar, although the magnitude of the theoretical curve is $\sim 100$ times larger than the experimental data. The main implication here is that not all the surface area of the individual particles is accessible to the adsorbate in the BET measurement. This is due to particle agglomeration causing the space between particles (pores) to be blocked off.

Also as part of the gas adsorption experiments the porosity of each sample was determined, as shown in Figure 4, which in this case is a plot of incremental pore area as a function of pore size. What is apparent with this data is that for those materials with high BET surface areas there are appreciable micro- $(<20 \AA)$ and meso- $(20$ $500 \AA$ ) pore volumes. Interestingly, the lowest surface area material, $\lambda-\mathrm{MnO}_{2}$, has no micro-pores at all, most likely as a result of particle sintering, and hence pore closure, during its thermal synthesis process. Another important observation is that the pore size distribution for $\beta$ $\mathrm{MnO}_{2}$ is similar in shape, but of lower intensity, compared to the $\gamma-\mathrm{MnO}_{2}$ pattern. Since the $\beta$ - phase material was derived from $\gamma$ $\mathrm{MnO}_{2}$ by heat-treatment, what is occurring here is a systematic closure of pores during the thermal treatment, again as a result of particle sintering.

Step potential electrochemical spectroscopy (SPECS).-Current vs Time Profiles. - Figure 5 shows a typical example of a potential step in a SPECS experiment, in this case obtained from a $\gamma-\mathrm{MnO}_{2}$ (EMD) electrode. The electrode was allowed to equilibrate at open circuit for 10 minutes. After this rest period the potential was stepped anodically by $25 \mathrm{mV}$ resulting in a large spike in current due to oxidation of the manganese oxide phase, after which it decays as the process becomes diffusion limited. The current approached zero as

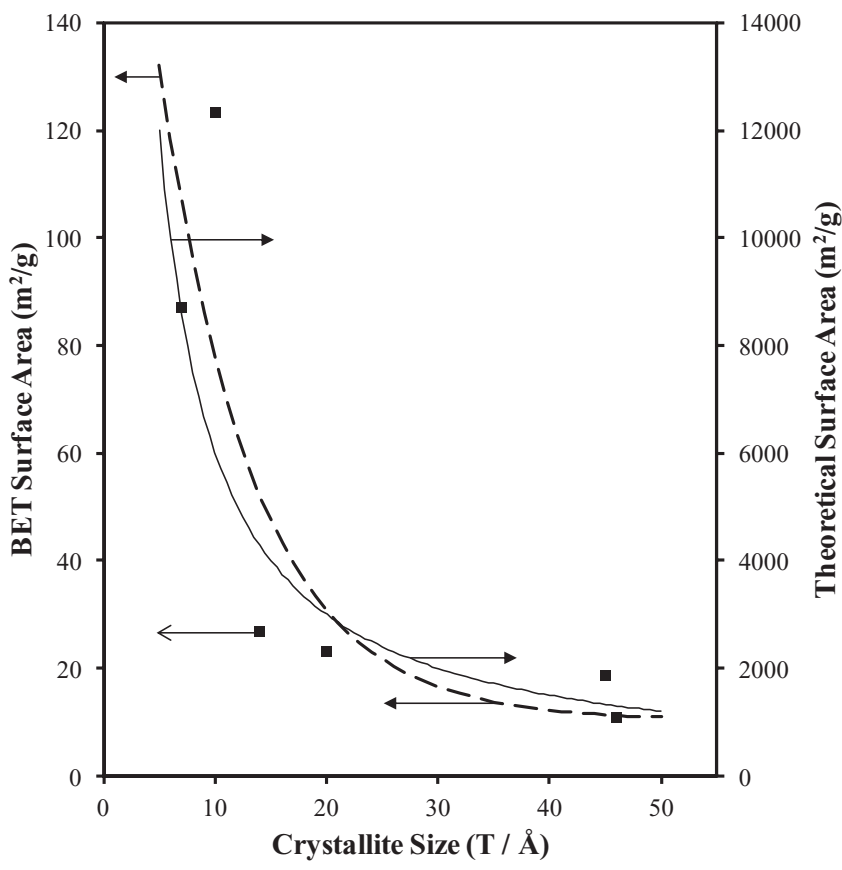

Figure 3. Relationship between crystallite size and BET surface area for the manganese dioxide samples examined. 


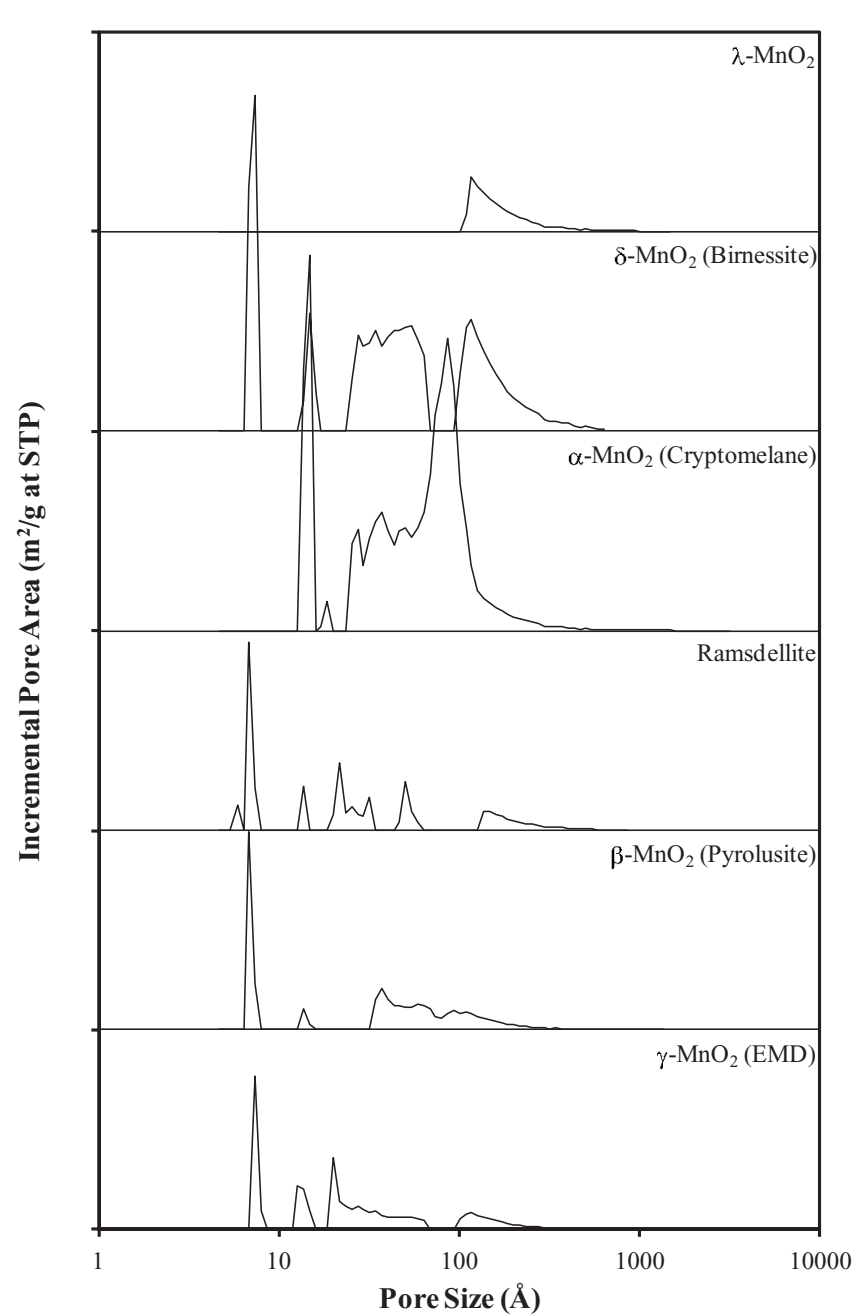

Figure 4. Porosity data, in terms of incremental pore surface area, for each of the manganese dioxide phases examined.

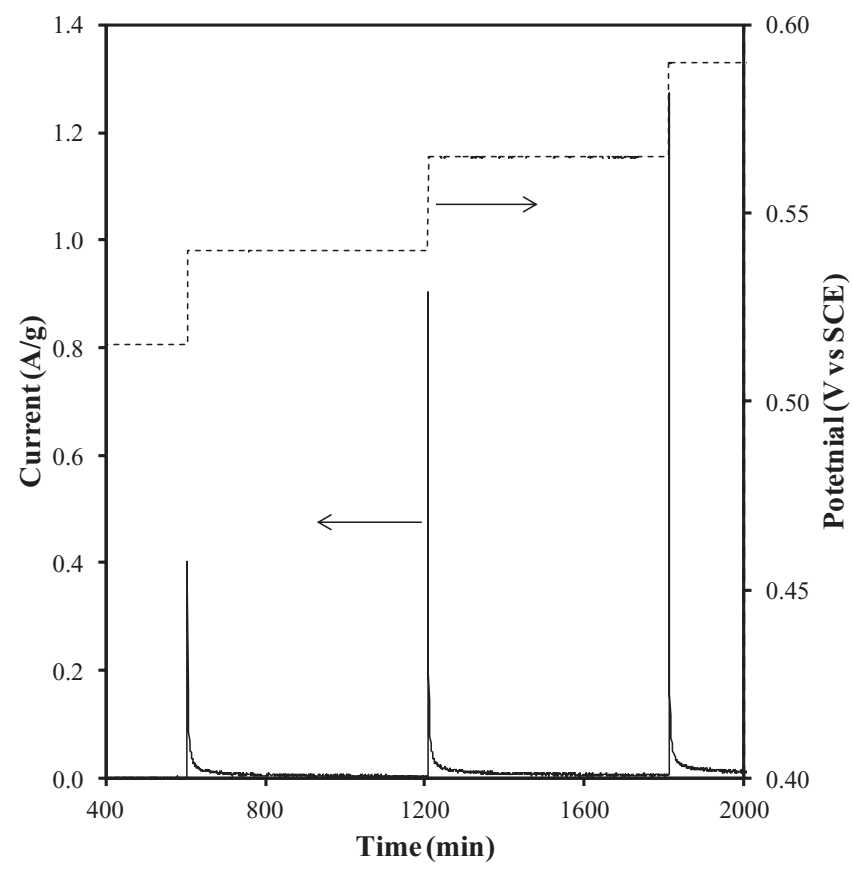

Figure 5. Segment of the step potential electrochemical spectroscopy (SPECS) data for the $\gamma-\mathrm{MnO}_{2}$ electrode. the rate of oxidation of the manganese oxide decreases due to slower diffusion and the consumption of active material. ${ }^{33}$ This potential step process was repeated until an upper potential of $0.8 \mathrm{~V}$ was reached, then the potential step sequence was reversed toward $0.0 \mathrm{~V}$, then again back up to $0.8 \mathrm{~V}$. For the purposes of this study, the data obtained from the SPECS experiment was used to calculate the degree of reduction of manganese dioxide ( $\mathrm{x}$ in $\mathrm{MnO}_{\mathrm{x}}$ ).

$x$ in $\mathrm{MnO}_{x}$. - To begin, the value of $\mathrm{x}$ in $\mathrm{MnO}_{\mathrm{x}}$ for each of the starting materials was determined using he potentiometric titration method described in the Experimental section. The results from this are also shown in Table I. Analysis of the $\gamma-\mathrm{MnO}_{2}$ sample was typical for an EMD $(x=1.965),{ }^{32}$ being slightly lower that the stoichiometric $\mathrm{x}$ $=2.000$ due to the presence of cation vacancies and $\mathrm{Mn}^{3+}$ ions in the structure. ${ }^{34-36}$ The $\beta-\mathrm{MnO}_{2}$ sample, which was derived from the $\gamma-\mathrm{MnO}_{2}$ sample, was expected to have an $\mathrm{x}$ in $\mathrm{MnO}_{\mathrm{x}}$ value closest to the stoichiometric value; however, its value $(\mathrm{x}=1.944)$ indicates that either the heat-treatment process has not fully removed cation vacancies from the structure, nor oxidized fully any $\mathrm{Mn}^{3+}$ present to $\mathrm{Mn}^{4+}$, or the thermal treatment has in fact been too severe in the sense that manganese dioxide has begun thermal reduction to form $\mathrm{Mn}_{2} \mathrm{O}_{3}$. The chemically precipitated materials, birnessite and cryptomelane, have appreciably lower $\mathrm{x}$ in $\mathrm{MnO}_{\mathrm{x}}$ values compared to the other phases. The main reason for this is that these materials were prepared in the presence of $\mathrm{K}^{+}$ions, which can be viewed as templating ions for these phases. As such, with $\mathrm{K}^{+}$ions being included in the structure, and to maintain charge neutrality, some of the manganese ions must be partially reduced to $\mathrm{Mn}^{3+}$. For the ramsdellite sample its $\mathrm{x}$ value was very similar to that of the $\gamma$ - phase. This was to be expected given the similarities, in terms of structural defects, between these two materials. The final phase, $\lambda-\mathrm{MnO}_{2}$ had an $\mathrm{x}$ value closest to the stoichiometric value. The reason why it was slightly reduced was because of residual $\mathrm{Li}^{+}$ions, and hence $\mathrm{Mn}^{3+}$ ions as well, in the structure.

During the SPECS experiment the degree of reduction for each material was calculated by first integrating the current as a function of time, giving the charge passed during each potential step. This was then used to determine the number of moles of starting material that had been either oxidized or reduced and therefore, the proportion of $\mathrm{Mn}^{3+}$ ions in each material. Figure 6 shows the $\mathrm{x}$ in $\mathrm{MnO}_{\mathrm{x}}$ profiles of each phase studied in this work.

All phases exhibit behavior consistent with the charge/discharge mechanism of manganese dioxide; c.f. Eqn 1. As the potential is stepped up from the OCP, the material is oxidized and cationic species and electrons are removed from the material, and so the value of $\mathrm{x}$ increases. For all phases, except for $\lambda-\mathrm{MnO}_{2}$, protons can be ejected from the structure upon charge. For the birnessite and cryptomelane phases, it is also possible that $\mathrm{K}^{+}$ions could be removed from the structure upon charge, although the presence of these ions does improve material stability. In the case of $\lambda-\mathrm{MnO}_{2}, \mathrm{Li}^{+}$ions are ejected from the structure upon the first charge. As the potential is decreased causing discharge of the electrode material, protons and electrons are primarily inserted into the material causing $\mathrm{x}$ to decrease. In the electrolyte used to cycle the electrode $\left(0.5 \mathrm{M} \mathrm{Na}_{2} \mathrm{SO}_{4}\right)$ there is also the possibility of $\mathrm{Na}^{+}$ions being intercalated into the host manganese dioxide structure; however, the evidence for this in the literature is not too convincing.

It should be noted in Figure 6 that upon charge the value of $x$ in $\mathrm{MnO}_{\mathrm{x}}$ increases beyond the thermodynamic limit $(\mathrm{x}=2.000)$ for some of the manganese dioxide phases. There are a number of possible explanations for this, the first being that some of the charge is used for another redox process such as oxygen evolution; ${ }^{37}$ i.e.,

$$
\mathrm{O}_{2}+4 \mathrm{H}^{+}+4 \mathrm{e}^{-} \leftrightarrow 2 \mathrm{H}_{2} \mathrm{O} \quad\left(\mathrm{E}_{0}=1.23 \mathrm{~V}\right)
$$

In the electrolyte used here the reversible potential for this redox couple, as calculated using the Nernst equation, is $0.575 \mathrm{~V}$ vs SCE (assuming neutral $\mathrm{pH}$ and impurity levels of $\mathrm{O}_{2}$ present), which is certainly within the electrochemical window being studied here. While kinetically the oxygen evolution reaction may be quite slow on the 
(a) $\gamma-\mathrm{MnO}_{2}$ (EMD)

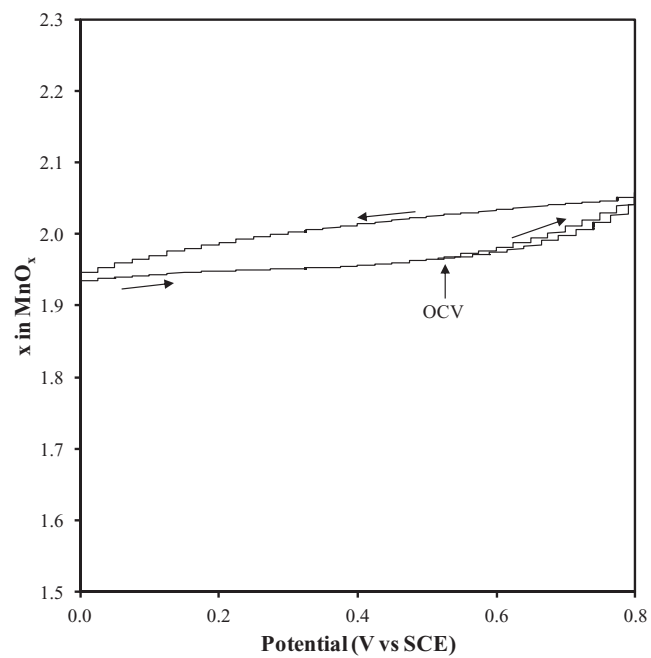

(c) Ramsdellite

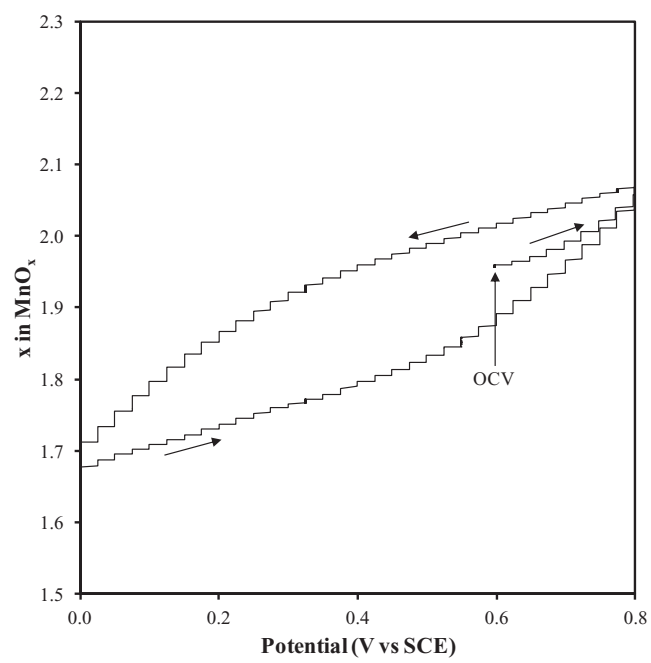

(e) $\delta-\mathrm{MnO}_{2}$ (Birnessite)

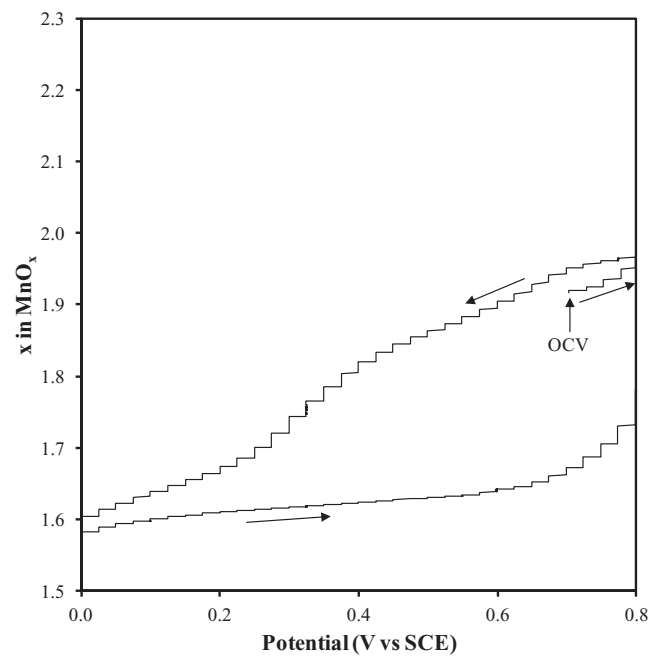

(b) $\beta-\mathrm{MnO}_{2}$ (Pyrolusite)

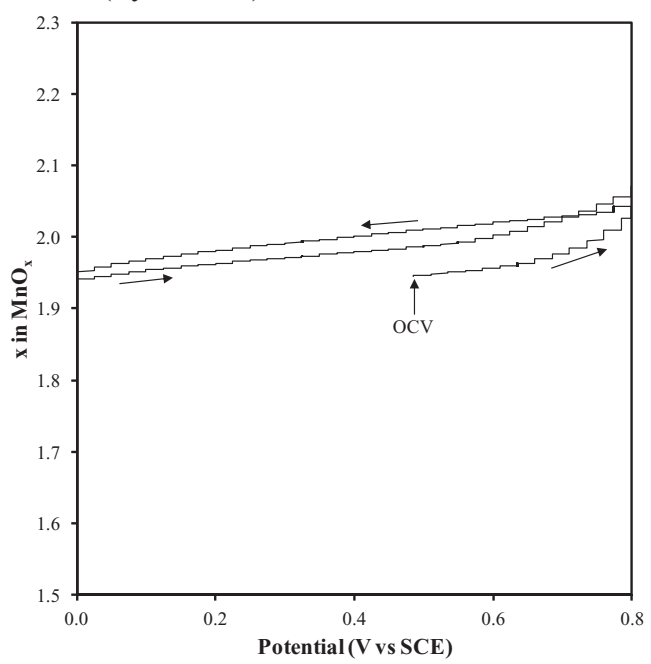

(d) $\alpha-\mathrm{MnO}_{2}$ (Cryptomelane)

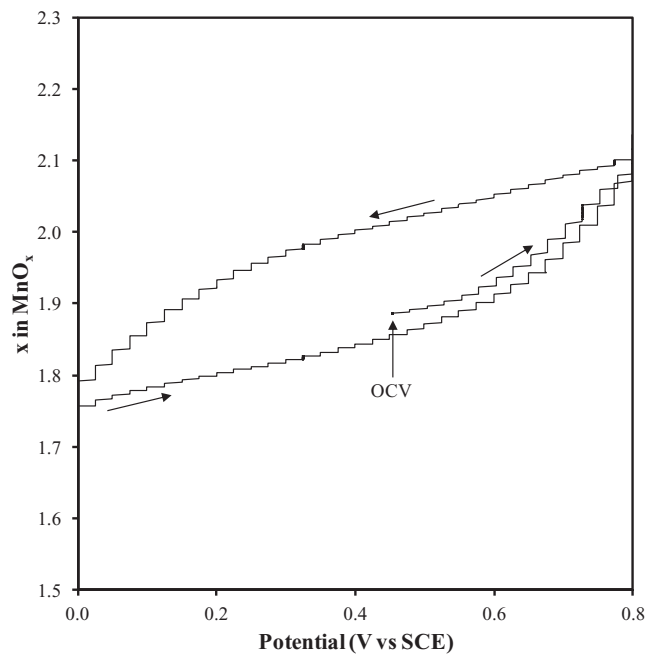

(f) $\lambda-\mathrm{MnO}_{2}$

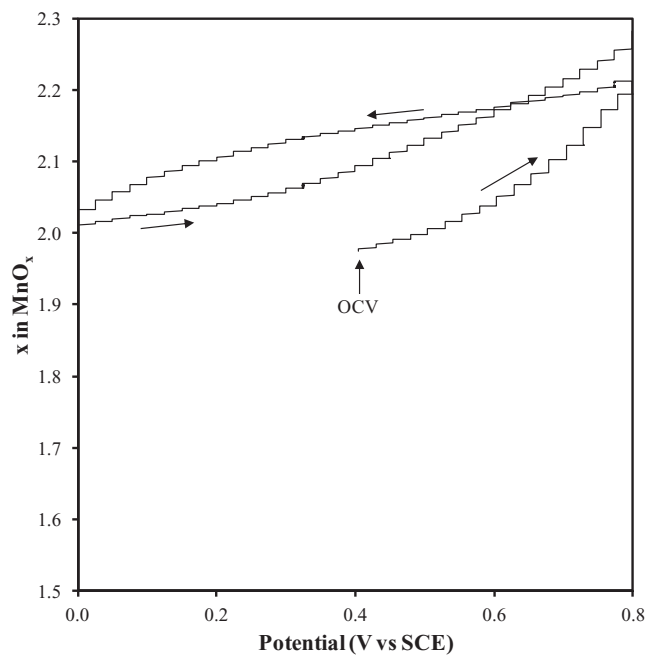

Figure 6. Compositional data $\left(\mathrm{x}\right.$ in $\left.\mathrm{MnO}_{\mathrm{x}}\right)$ for each of the manganese dioxide phases studied, as determined from their corresponding SPECS experiment. 
manganese dioxide surface, given the relatively slow discharge rate used during the SPECS experiments ( $25 \mathrm{mV}$ every 10 minutes) it is possible that appreciable charge could be used for oxygen evolution. Similarly, further oxidation of the manganese dioxide to form, for example, permanganate $\left(\mathrm{MnO}_{4}{ }^{-}\right)$is also thermodynamically possible; ${ }^{37}$ i.e.,

$$
\mathrm{MnO}_{4}^{-}+4 \mathrm{H}^{+}+3 \mathrm{e}^{-} \leftrightarrow \mathrm{MnO}_{2}+2 \mathrm{H}_{2} \mathrm{O} \quad\left(\mathrm{E}_{0}=1.69 \mathrm{~V}\right)
$$

In this electrolyte the reversible potential for this reaction is $0.779 \mathrm{~V}$ vs SCE, again assuming neutral $\mathrm{pH}$ and impurity levels of $\mathrm{MnO}_{4}{ }^{-}$. As with oxygen evolution, this reaction is also expected to be kinetically quite slow, particularly given the low overpotential applied to this reaction. Another possible explanation, one that is particularly relevant to the study of supercapacitors, is that the excess charge above $\mathrm{x}=2.000$ could be due to charge storage in the double layer at the manganese dioxide - electrolyte interface. While the surface area of these phases is nowhere near that of typical supercapacitor electrode materials such as activated carbon $\left(>2000 \mathrm{~m}^{2} / \mathrm{g}\right)$, it is still possible for charge to be stored in this way, particularly so at the high potential, fully charged region of the voltammogram.

The data in Figure 6 can be used to evaluate the reversibility of the proton (cation) insertion/de-insertion process. For example, $\gamma-\mathrm{MnO}_{2}$ shows a high degree of reversibility, as evident from the near overlap of $\mathrm{x}$ values in the first charge to $0.8 \mathrm{~V}$ and the second complete charge. Any irreversibility in the reaction would be manifest as a significant change in the $\mathrm{x}$ values before and after cycling. No such behavior is evident, indicating that the diffusion properties of $\gamma-\mathrm{MnO}_{2}$ are reversible during cycling. Similar behavior was also observed for the cryptomelane and ramsdellite phases, which indicates that these materials also undergo a reversible cycling. Both phases also undergo reduction to a relatively large extent, with $\mathrm{x}$ values in ramsdellite decreasing to a minimum of 1.670 when fully discharged.

Pyrolusite and $\lambda-\mathrm{MnO}_{2}$ behave somewhat differently, with both phases exhibiting a significant change in composition during charging. Birnessite exhibits entirely different behavior to the other phases. Upon reduction the composition changes significantly, reaching a lower limit of $x=1.582$. During the subsequent charging process, the material is not reversibly oxidized, reaching a maximum $x$ value of only 1.728. This implies that birnessite has undergone an irreversible phase change during discharge. This behavior has been previously reported in the literature, ${ }^{38}$ and it is suggested that the material undergoes reduction from its original structure to the more thermodynamically stable $\mathrm{Mn}_{3} \mathrm{O}_{4}$, a species which does not display redox activity in this potential range.

As a final in this section, the extent of reduction that these different phases of manganese dioxide undergo also varies considerably, and under the electrochemical conditions used, reflects both limitations in the thermodynamic potential window for each different phase, and the kinetics of mass transport for the intercalated species.

Electrochemical impedance spectroscopy (EIS).- Data.- EIS data from this experiment is most effectively displayed as a Nyquist plot, in which each impedance measurement taken at a given frequency is plotted as the complex function of its imaginary $\left(Z^{\prime \prime}\right)$ and real impedance $\left(Z^{\prime}\right)$. This allows the total impedance of the cell $(Z)$ to be separated into its resistive $\left(Z^{\prime}\right)$ and capacitive $\left(Z^{\prime \prime}\right)$ components. The shape of this plot can be used as an indication of the types of processes occurring at the electrode. Generally, at low frequencies the behavior is mass transport limited, and the cell exhibits relatively high impedance. As the frequency is increased, the impedance decreases and the data exhibits a linear relationship. These values are mostly used to extract properties of the electrode which contribute to mass transport.

The high frequency region of the data represents the charge transfer and double layer capacitive processes occurring in parallel at the electrode. These processes form a semi-circular arc within the Nyquist plot. At very high frequencies, the electrode exhibits purely resistive behavior which is indicative of the cell series resistance. (a) Discharge

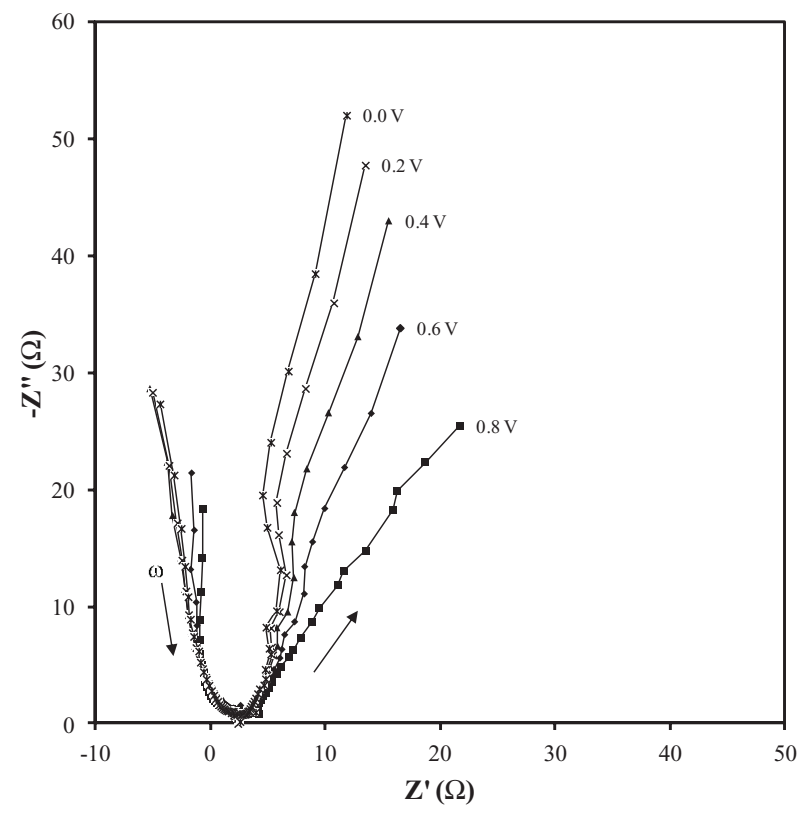

(b) Charge

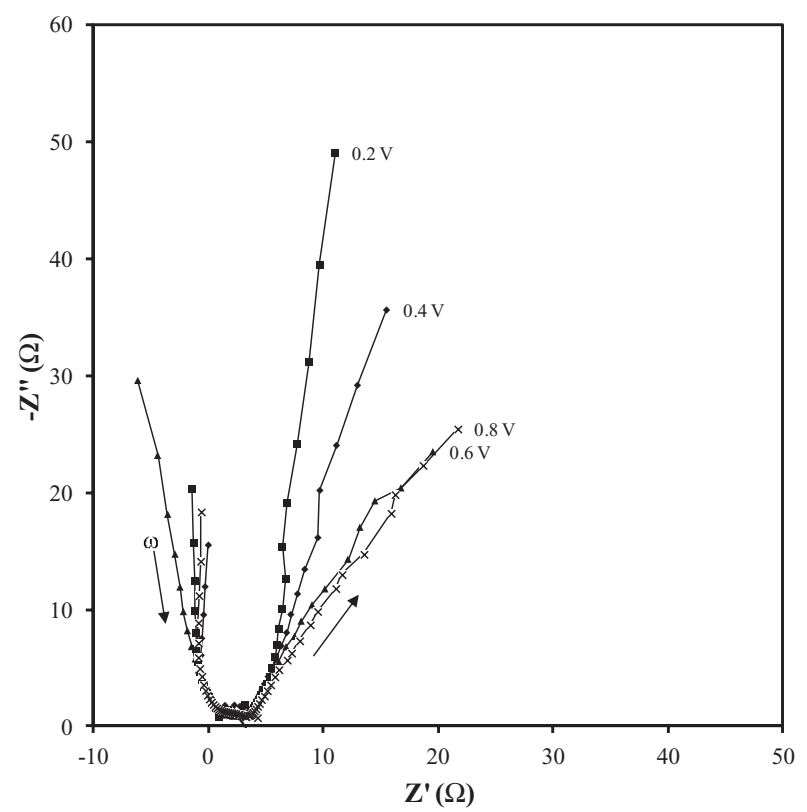

Figure 7. Impedance spectra for the $\gamma-\mathrm{MnO}_{2}$ electrode at selected potentials during the (a) discharge and (b) charge half cycles. Arrows show direction of decreasing frequency.

EIS Changes with Potential and Degree of Reduction.-This understanding of EIS can be applied to the analysis of the impedance spectra of the electrode materials as a function of potential, and ultimately the degree of reduction. As an example, Figure 7 shows the impedance spectra of $\gamma-\mathrm{MnO}_{2}$ electrode at various potentials during the charge and discharge half cycles. The diffusion limited region can be readily identified by the linear increase in impedance with decreasing frequency. The electrode shows a systematic change in the parameters defining mass transport with changing potential, as evident from the change in the slope of the low frequency portion of the data. The plot also shows a poorly defined semi-circular arc at low and intermediate frequencies. In this set of experiments, $\gamma-\mathrm{MnO}_{2}$ is unique in exhibiting a significant increase in imaginary impedance at the highest 
frequencies. This behavior is unusual as it implies that the resistance in the set of real impedance values is negative. Given that this cannot be due to any physical process, it is likely an artifact of the experimental method, most likely the phase angle shift. In particular, this experiment involved the application of a sinusoidal potential to the working electrode. The current response was measured in terms of its amplitude and phase angle $(\phi)$ between it and the potential. In most cases, the current lags behind the potential by this phase angle. In the extreme case where the current lags the potential by $\phi>\pi$ radians the phase angle can be interpreted as being positive. Electrochemically, this implies that the current is preceding the applied potential, leading to negative resistance values. The implication is that the electrode material has extremely slow kinetics at very high frequencies and is likely caused by interference from the substrate.

Comparison Between Phases.-The other phases of manganese dioxide studied in this work show similar behavior to the $\gamma-\mathrm{MnO}_{2}$ electrode. As an example, Figure 8 shows the spectra of each phase taken at $0.6 \mathrm{~V}$ vs SCE in the discharge cycle. The most significant difference
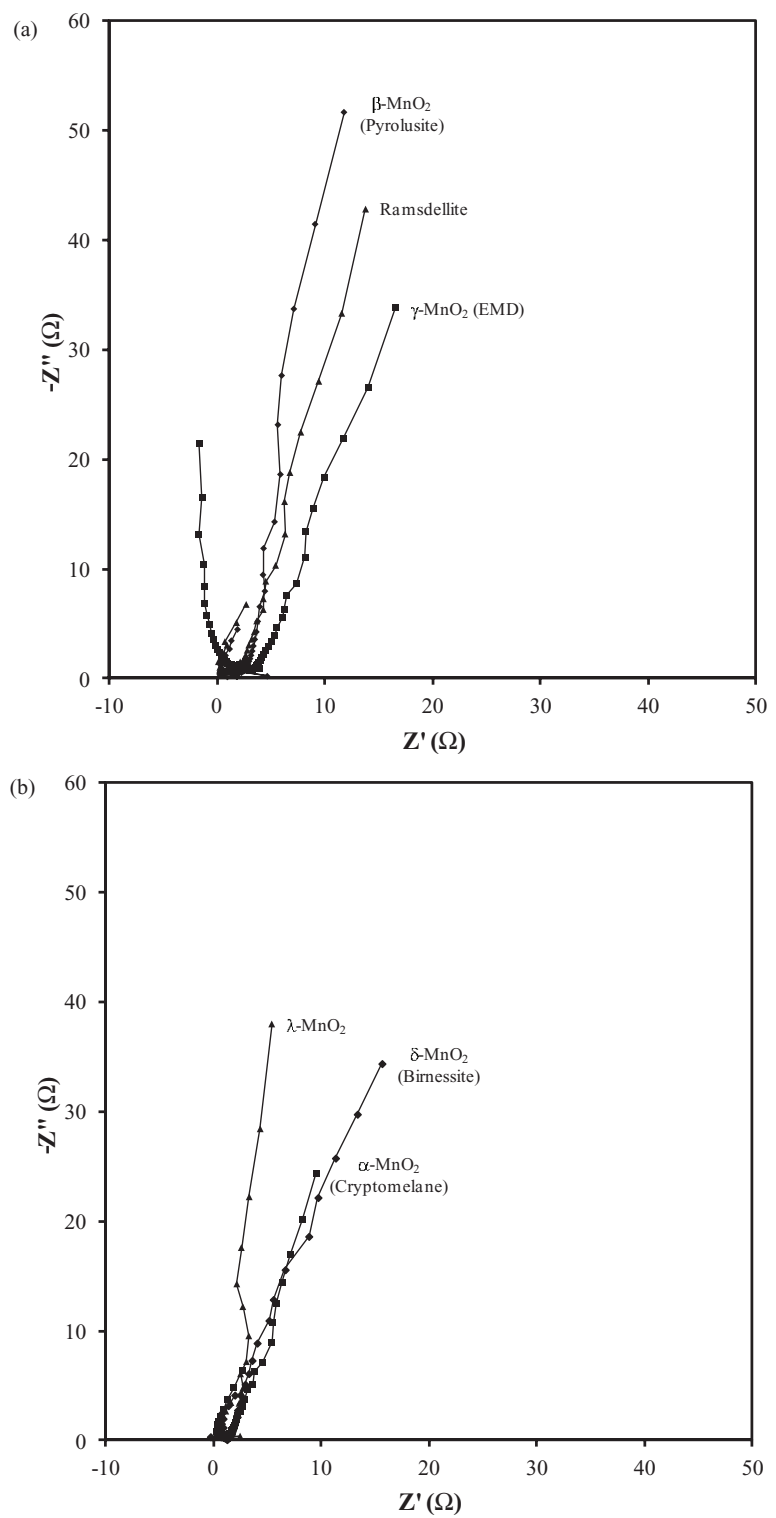

Figure 8. EIS comparison between different manganese dioxide phases (a) $\gamma-\mathrm{MnO}_{2}$ (EMD), $\beta-\mathrm{MnO}_{2}$ (Pyrolusite) and Ramsdellite, and (b) $\alpha-\mathrm{MnO}_{2}$ (Cryptomelane), $\delta-\mathrm{MnO}_{2}$ (Birnessite) and $\lambda-\mathrm{MnO}_{2}$. Potential $=0.6 \mathrm{~V}$ vs SCE.

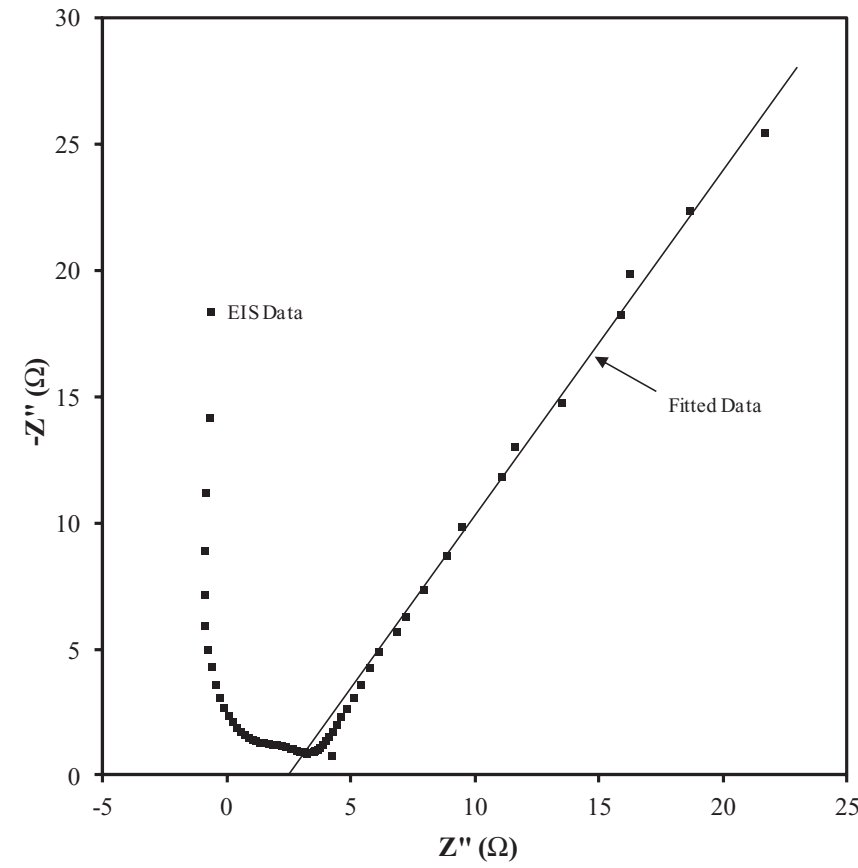

Figure 9. Example of the equivalent circuit modeling of the low frequency portion of the EIS data, in this case for a $\gamma-\mathrm{MnO}_{2}$ electrode at $0.8 \mathrm{~V}$ vs SCE. The equivalent circuit model is shown in Figure 10.

between the phases is the diffusion behavior, as evident from the comparison between the low frequency impedance data. However, unlike $\gamma-\mathrm{MnO}_{2}$, the other phases do not exhibit negative $\mathrm{Z}^{\prime}$ values at high frequencies, rather the total impedance of the cell increases with positive $\mathrm{Z}^{\prime}$ values. This behavior has not been attributed to any physical electrode process, as mentioned before, and is thought to be an effect caused by the titanium substrate and/or cell construction.

Analysis of Equivalent Circuit Parameters.-The most effective way to quantitatively compare the behavior of each electrode material at different potentials is to fit the measured impedance data to an equivalent circuit. For the data sets collected here, only the mass transport processes were analyzed, corresponding to the linear region at lower frequencies. This frequency region and the associated equivalent circuit fitting is shown in Figure 9. The equivalent circuit for this process is relatively simple, and consists of a resistor in series with a constant phase element, as shown in Figure 10. The resistor is defined by a single value $(\mathrm{R} ; \Omega)$, whilst the constant phase element is defined by two parameters, $\sigma$ and $\mathrm{m}$. The impedance of the equivalent circuit in Figure 10 is therefore given by:

$$
Z=R+\sigma \omega^{-m}\left\{\cos \left(\frac{m \pi}{2}\right)-j \sin \left(\frac{m \pi}{2}\right)\right\}
$$

where $\mathrm{Z}$ is the total impedance $\left(\mathrm{Z}^{\prime}+\mathrm{j} \mathrm{Z}^{\prime \prime}\right), \omega$ angular frequency $(\mathrm{rad} / \mathrm{s})$, and $\mathrm{j}$ the imaginary number $(\sqrt{-1})$. The equivalent circuit in Eqn 13 was fitted to the experimental data (over an appropriate frequency range) using the complex non-linear least squares regression function in the ZView software package to provide optimal quantities for the three fitted parameters; i.e., R, $\sigma$ and $\mathrm{m}$.

Quantifying mass transport characteristics-determining $A \sqrt{ } D$.The equivalent circuit parameters determined from the modeling of

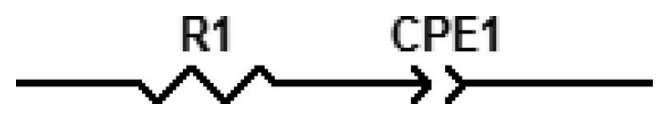

Figure 10. Equivalent circuit used to model the low frequency portion (diffusion tail) of the manganese dioxide EIS data. 
the EIS data can be used to characterize the kinetics of solid state mass transport using a method similar to that described by $\mathrm{Qu},{ }^{39,40}$ and used by us previously in the study of battery materials. The key assumption in the method is that diffusion in the solid state is semiinfinite in nature, which is reasonable given that $\omega>>\mathrm{D} / l^{2}$ (derived from the Einstein-Smoluchowski equation ${ }^{41}$ ), where $\mathrm{D}$ is the diffusion coefficient $\left(\mathrm{m}^{2} / \mathrm{s}\right)$ and $l$ is the length of the diffusion pathway, or crystal radius in this case. Based on this, $\mathrm{A} \sqrt{ } \mathrm{D}$ can be extracted from the EIS data using the expression: ${ }^{33}$

$$
\mathrm{A} \sqrt{\mathrm{D}}=\frac{\mathrm{RT}}{\sigma \mathrm{F}^{2} \sqrt{2}\left[\mathrm{H}^{+}\right]}
$$

where $A$ is the electrochemically active surface area $\left(\mathrm{m}^{2}\right), \mathrm{D}$ is the proton diffusion constant $\left(\mathrm{m}^{2} / \mathrm{s}\right), \mathrm{R}$ is the standard gas constant $(8.3143$ $\mathrm{J} / \mathrm{K} / \mathrm{mol}$ ), T is the temperature $(\mathrm{K}), \sigma$ is determined from the EIS equivalent circuit modeling $(\Omega), \mathrm{F}$ is Faradays constant $(96486.7 \mathrm{C} / \mathrm{mol})$, and $\left[\mathrm{H}^{+}\right]$is the effective solid-state proton concentration $\left(\mathrm{mol} / \mathrm{m}^{3}\right)$.

The concentration of protons in the solid state manganese dioxide structure will be calculated from the unit cell volume data determined previously and reported in Table $\mathrm{I}$, as well as the $\mathrm{x}$ in $\mathrm{MnO}_{\mathrm{x}}$ data which provides us with the moles of protons in the unit cell. The conversion between $\mathrm{x}$ in $\mathrm{MnO}_{\mathrm{x}}$ and mole fraction of protons in the manganese dioxide structure $\left(\mathrm{r}\right.$ in $\left.\mathrm{MnOOH}_{\mathrm{r}}\right)$ is given by: ${ }^{32}$

$$
r=4-2 x
$$

The main assumption with calculating the solid state proton concentration this way is that the unit cell volume remains constant with depth of discharge. There is evidence in the literature, ${ }^{42,43}$ particularly for the $\gamma-\mathrm{MnO}_{2}$ phase, that its structure expands with discharge, mainly due to the incorporation of $\mathrm{Mn}^{3+}$ ions, which have a larger ionic radius compared to $\mathrm{Mn}^{4+}$ (ionic radii comparison), rather than the presence of $\mathrm{OH}^{-}$compared to $\mathrm{O}^{2-}$. However, from these reports, the structure expands $\sim 10 \%$ from its original composition down to a fully discharged material. For the other manganese dioxide phases examined here there is no literature information available on structural expansion with depth of discharge, and so given the fractional discharge experienced by most materials, we will carry out the remainder of our calculations assuming a constant initial unit cell volume.

Analysis of $A \sqrt{ } D$.- Changes With Potential and Composition.The $A \sqrt{ } \mathrm{D}$ values at each potential for each phase of manganese dioxide were calculated and plotted as a function of potential in Figure 11. All of the phases exhibited a decrease in $A \sqrt{ } D$ as the material was discharged, and an increase upon charging. This behavior can be related to the mechanism by which protons and other cations move through the manganese dioxide crystal lattice. Protons move through the lattice by hopping between adjacent $\mathrm{O}^{2-}$ anions, with their rate of diffusion being dependent on the activation energy for hopping, which is in turn influenced by the distance between adjacent hop sites. When an electron is inserted into the lattice at the crystallite surface, reducing a $\mathrm{Mn}^{4+}$ ion to $\mathrm{Mn}^{3+}$, a proton from the electrolyte is also inserted to account for charge neutrality. As has been discussed previously in the preceding section, the inserted electron and proton cause the unit cell to expand slightly. This increase in distance between adjacent hop sites that occurs as a result of structural swelling, slows the movement of protons through the lattice because they now have further to hop. In the reverse sense, when the electrode is charged electrons and protons are removed from the material and the lattice contracts, correspondingly increasing the diffusion coefficient.

Analysis of the $\gamma-\mathrm{MnO}_{2}$ Electrode.-The $\gamma-\mathrm{MnO}_{2}$ phase is interesting to examine since it is the phase of material that has been studied the most extensively in the literature due to its history as a battery cathode material. As this material is discharged, $A \sqrt{ } D$ decreases very rapidly with potential, which suggests a consistent rate of lattice expansion with proton insertion. The exact opposite behavior was also observed as the material was then charged, as evident from the overlap of data points within the potential range $0.00-0.35 \mathrm{~V}$. However, at high er potentials during charging a significant hysteresis loop is observed, indicating a change in material behavior when moving to higher potentials. This hysteresis may be attributed to a decrease in the kinetics of lattice contraction hindering the movement of protons through the material. It is interesting to note that this hysteresis is evident only at potentials $>0.35 \mathrm{~V}$, while below this potential the material appears to undergo reversible lattice expansion and contraction processes. These results suggest that there are multiple diffusion processes occurring during cycling - a characteristic which has been observed before ${ }^{44}$ and can be related to the structure of $\gamma-\mathrm{MnO}_{2}$.

$\gamma-\mathrm{MnO}_{2}$ does not have a uniform crystal structure, with many different structural domains existing within the material. There are defects, such as cation vacancies, structural water and microtwinning, and the material contains micro-domains of intergrown pyrolusite and ramsdellite phases. ${ }^{30,34-36}$ These structural features result in energetically different domains which are reduced at different potentials.

The change in $\mathrm{A} \sqrt{ } \mathrm{D}$ at different potentials could indicate diffusion of protons through two different structural domains, where the diffusion at lower potential represents a more reversible domain. Browning et al., ${ }^{44}$ identified a number of energetically different domains which contributed to the total proton diffusion in $\gamma-\mathrm{MnO}_{2}$. Higher potential processes have been attributed to the reduction of $\mathrm{Mn}^{4+}$ on or near the surface of the active material, and/or near defects in the structure. These processes have been found to have high $A \sqrt{ } D$ values of $2.3 \times 10^{-2} \mathrm{~cm} / \mathrm{s}^{1 / 2} / \mathrm{g}$, which is in agreement with the data presented here. The reason for higher $A \sqrt{ } D$ values in these structural domains is due to lateral or surface diffusion of protons, assisted by the availability of protons from the electrolyte. ${ }^{44}$ High energy cation vacancies are also thought to assist the dispersion of protons which would lead to an increased diffusion coefficient. ${ }^{34}$ Despite the high $A \sqrt{ } \mathrm{D}$ values associated with this process, the results here indicate that the kinetics of lattice contraction are relatively slow. This could be due to less reversible surface processes, such as ion adsorption, restricting the ability of the lattice to contract.

There have been a number of different domains through which diffusion occurs at lower potentials, including diffusion through the ramsdellite and pyrolusite phases of the material. However, there is often significant overlap between these processes. Since only two processes have been identified in this data, it would be reasonable to conclude that the lower potential processes are due to proton diffusion through the bulk structure of the material.

Comparison Between Other Phases.-When identifying the bulk and surface properties, and their contribution to $A \sqrt{ } D$, it is important to also consider the surface areas of different phases. The $\gamma-\mathrm{MnO}_{2}$ sample examined here has a surface area of $26.8 \mathrm{~m}^{2} / \mathrm{g}$, so it provides an intermediate reference point with which to compare the other phases. Phases such as ramsdellite $\left(23.2 \mathrm{~m}^{2} / \mathrm{g}\right)$ and cryptomelane $\left(123.3 \mathrm{~m}^{2} / \mathrm{g}\right)$, exhibit a much greater hysteresis across the entire potential range. Assuming that the hysteresis is due to slower kinetics of surface domains, this suggests that most of the diffusion is occurring at the surface of the material. Given the relatively high surface area of these materials, these results support this hypothesis. Overall, ramsdellite displays diffusion coefficients that are slightly lower than $\gamma-\mathrm{MnO}_{2}$. Cryptomelane exhibited similar behavior but with much lower values for $A \sqrt{ } D$ over the entire range. These low values have been attributed to the much larger tunnel size within the structure, which results in a larger hop distance between allowed proton sites. ${ }^{45}$ Whilst $\gamma-\mathrm{MnO}_{2}$, ramsdellite and cryptomelane all exhibit considerable hysteresis, ultimately the charge/discharge process is almost entirely reversible. The values for A $\sqrt{ } \mathrm{D}$ before and after charging are approximately the same indicating that the diffusion properties of the material have returned to the pre-cycled state.

Conversely, pyrolusite and $\lambda-\mathrm{MnO}_{2}$ have much lower surface areas (18.6 and $10.8 \mathrm{~m}^{2} / \mathrm{g}$, respectively) than $\gamma-\mathrm{MnO}_{2}$, and these phases both exhibit behavior consistent with bulk proton diffusion. This must be 
(a) $\gamma-\mathrm{MnO}_{2}(\mathrm{EMD})$

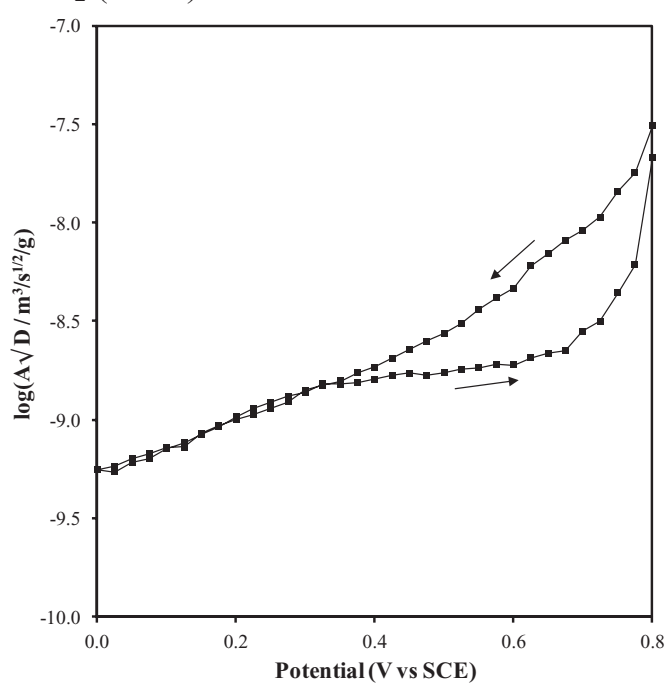

(c) Ramsdellite

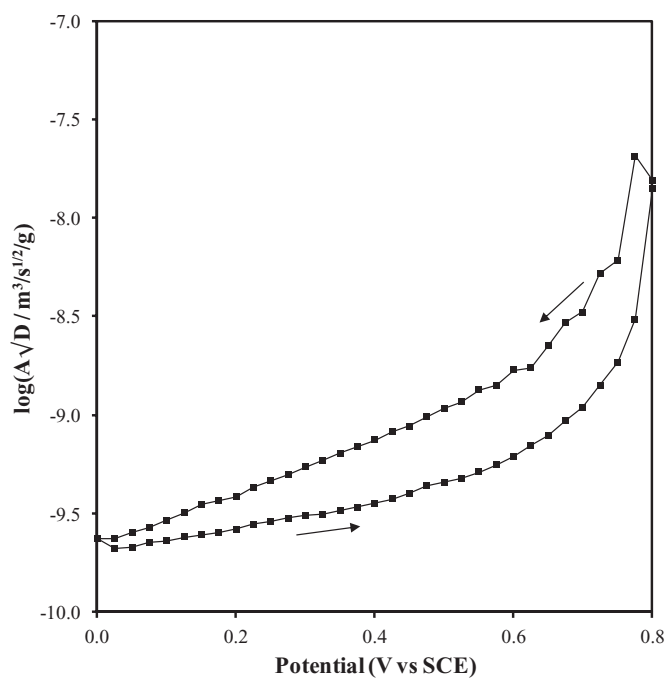

(e) $\delta-\mathrm{MnO}_{2}$ (Birnessite)

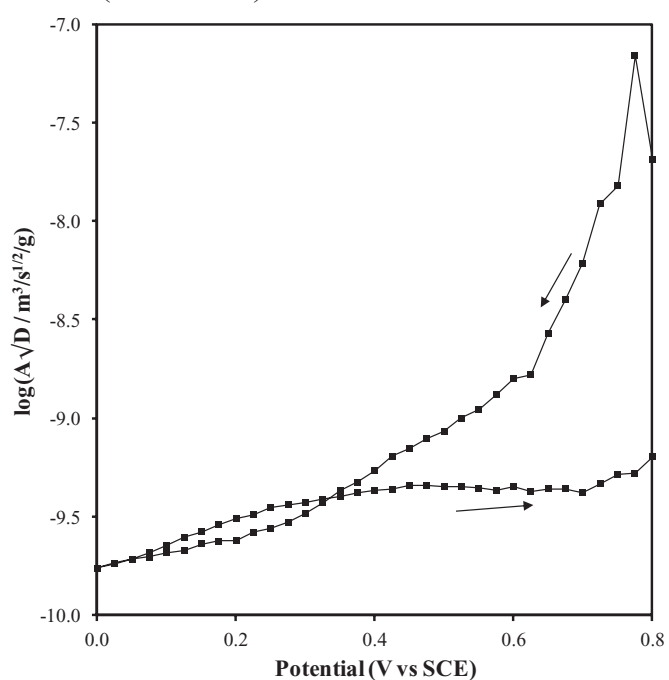

(b) $\beta-\mathrm{MnO}_{2}$ (Pyrolusite)

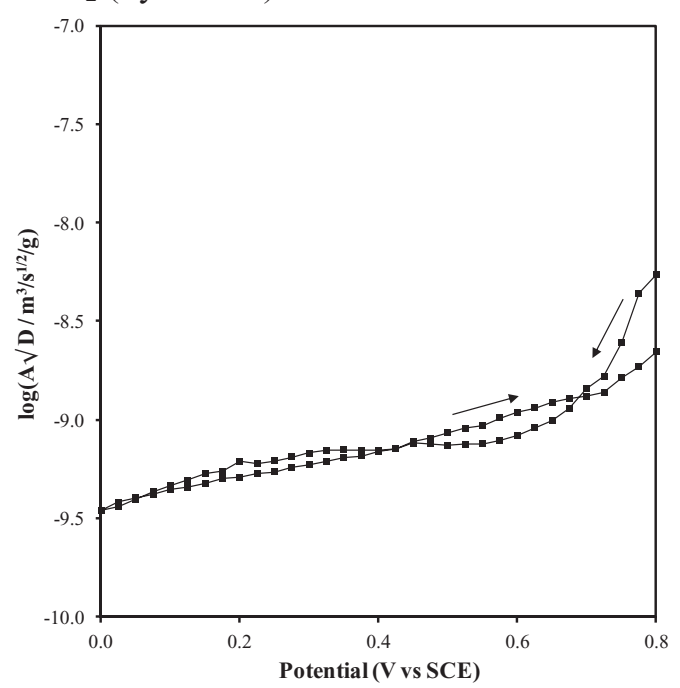

(d) $\alpha-\mathrm{MnO}_{2}$ (Cryptomelane)

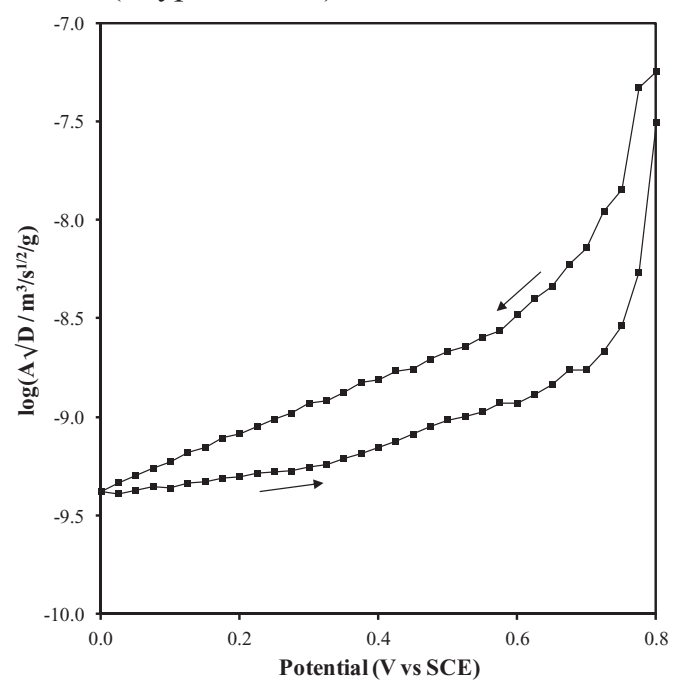

(f) $\lambda \mathrm{MnO}_{2}$

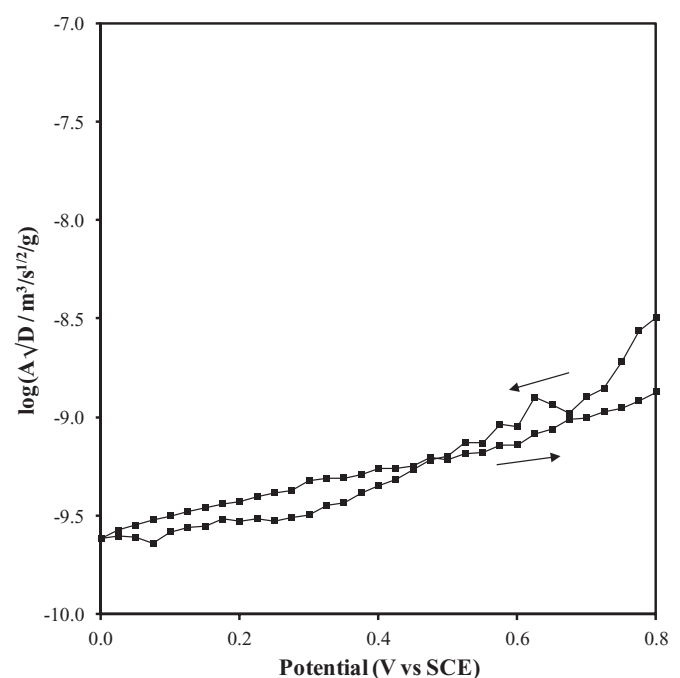

Figure 11. Plot of $\log (A \sqrt{ } D)$ for all the manganese dioxide phases studied in this work. 
expected, given the proportion of the material that is available for surface diffusion, relative to the bulk material. Both of these phases show reversible diffusion behavior at lower potentials, and pyrolusite exhibits a very slight hysteresis at higher potentials. However over the complete cycle, these phases show irreversible behavior in the form of a decrease in $A \sqrt{ } D$ in the fully charged state. This behavior was also observed in the $\mathrm{x}$ in $\mathrm{MnO}_{\mathrm{x}}$ profiles for these materials.

Birnessite has the highest maximum $A \sqrt{ } D$ values out of all the phases examined. However, it does exhibit a significant decrease in $A \sqrt{ } D$ during the initial discharge. Upon charging, the diffusion coefficient increases up to $\sim 0.35 \mathrm{~V}$, after which it plateaus. This indicates again that an irreversible phase change has occurred in the material. This behavior is mirrored in the SPECS analysis of birnessite ( $x$ in $\mathrm{MnO}_{\mathrm{x}}$ ) which shows a significant, irreversible change in the depth of discharge properties of the material. As proposed before, the birnessite undergoes a phase change to form $\mathrm{Mn}_{3} \mathrm{O}_{4}$ upon reduction. This is a significant irreversible structural change which will definitely further affect its electrochemical performance.

Surface Area Considerations.-The previous analysis of mass transport in the various manganese dioxide phases yields values for $A \sqrt{ } D$ which cannot be reliably separated into the diffusion and area components due to the difficulty in accurately measuring the electrochemically active surface area of the electrode material. As a first approximation the geometric surface area of particles within the sample could be used; however, this assumption neglects the effects of porosity on surface area, as well as being very difficult to include the effects of particle morphology into the calculation. A more useful approximation for the electrochemically active surface area of the material can be obtained from its BET surface area, as has been measured for each phase in this study. This is the most appropriate method for porous materials as the gaseous surface probe can access the pores. However, from an electrochemical perspective, this latter point is the greatest source of error in the method since there is a difference in the accessibility of $\mathrm{N}_{2}$ gas into the substrate pores at $77 \mathrm{~K}$ compared to solvated electrolyte ions at ambient temperature. It is expected that the electrolyte ions do not have as good an access to smaller pores present in the material, and hence the specific surface area is expected to be lower than the BET surface area. However, studies by Soffer et al. ${ }^{46,47}$ concluded that the micro-pores accessible to $\mathrm{N}_{2}$ are also accessible to hydrated ions and water molecules at low electrochemical discharge rates. Hence, the BET surface area of the material can be regarded as the most reliable estimate of the electrochemically active surface area of the starting material. Therefore, Figure 12 shows the diffusion coefficient (D) profiles which have been derived from $A \sqrt{ } D$ with $A$ being the BET surface area.

There are, however, some limitations to using this approximation. This approach assumes that the specific surface area remains constant as a function of depth of discharge, whereas a number of reports indicate that the specific surface area changes as the material is cycled. ${ }^{41}$ This change in surface area occurs when the manganese dioxide crystallites expand during reduction causing the closure of pores, which reduces the area accessible to the electrolyte. ${ }^{48}$

$\mathrm{Qu}^{39}$ used this approximation for calculating the diffusion coefficient of protons in EMD in an alkaline electrolyte and found values to be in the range $10^{-15}-10^{-16} \mathrm{~cm}^{2} / \mathrm{s}$, over a similar potential range. The diffusion coefficient values presented here vary between $10^{-14}-10^{-18} \mathrm{~cm}^{2} / \mathrm{s} / \mathrm{g}$ which represents a much larger variation. This may indicate that assuming a constant BET surface area is not a valid approximation. Taking this into consideration, it is more accurate to examine the change in $A \sqrt{D}$ as a function of potential for each phase.

Electrochemical performance evaluation.- Cyclic voltammetry was used to evaluate the overall performance of each phase to determine its specific capacitance. For any supercapacitor electrode material its performance is governed by a number of material properties including the intrinsic capacitance $\left(\mathrm{F} / \mathrm{m}^{2}\right)$, which is a function of the surface density of charge storage sites, and the material porosity, which dictates the accessibility of electrolyte ions to the electrode surface.

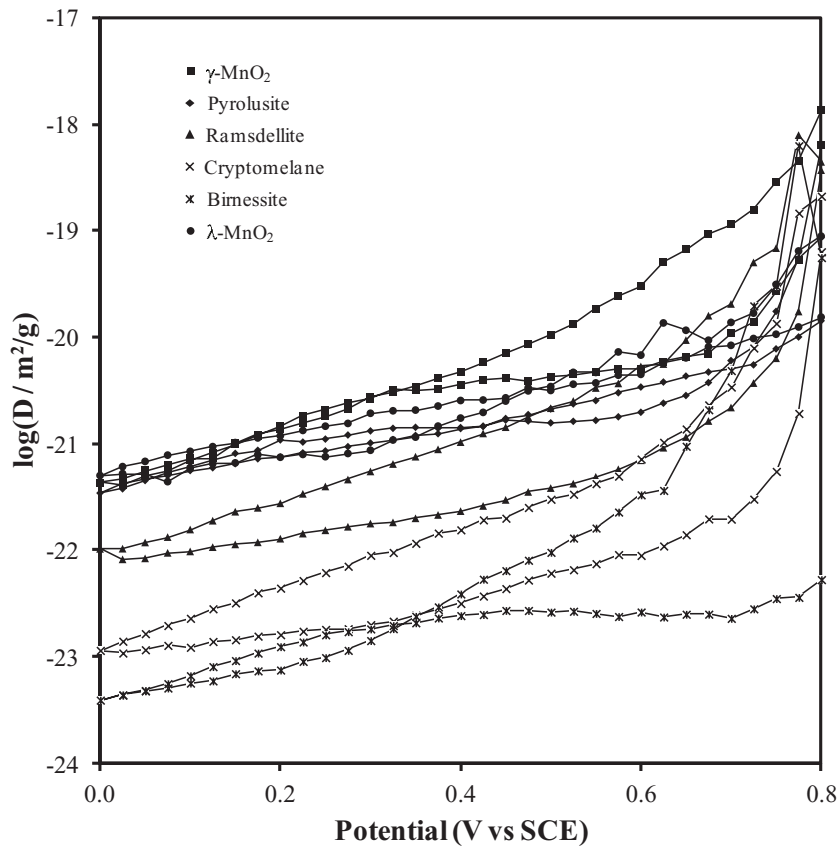

Figure 12. Calculated values of the solid state proton diffusion coefficient for the variety of manganese dioxide phases examined in this study. The area employed was the BET surface area.

For materials that exhibit pseudo-capacitance there are other factors such as the kinetics of charge transfer at the electrode-electrolyte interface, as well as mass transport through the crystal structure, as has been examined in this study.

All of the manganese dioxide phases examined in this study exhibited a roughly rectangular voltammogram, typical of capacitive electrodes, as shown in Figure $13\left(50^{\text {th }}\right.$ cycle for each manganese dioxide phase). The only exception is at high potentials during an anodic sweep, in which case the current increases above that of the roughly rectangular voltammogram, perhaps due to a specific oxidation process within the manganese dioxide. The inset data in each graph in Figure 13 corresponds to the cyclability of each phase. The specific capacitance shows a significant decrease during the first 10 cycles, but approaches a constant value as the electrode reaches a steady state. The specific capacitance of the material is recorded as the capacitance at the $50^{\text {th }}$ cycle, as also shown in Table I.

These specific capacitance values suggest that the $A \sqrt{ } D$ values do not directly correlate with the overall charge storage capabilities of the manganese dioxide, implying a combination of material property effects. Cryptomelane exhibits the highest specific capacitance despite having a very low diffusion coefficient, suggesting that in this material, the predominant charge storage mechanism is not proton intercalation, but rather related to surface charge storage since this phase has a high BET surface area. Reported specific capacitance values for cryptomelane are similarly high, with values ranging from 125-297 F/g. ${ }^{49-51}$ It has been proposed that the high specific capacitance of $\alpha-\mathrm{MnO}_{2}$ structures can be attributed to cation intercalation contributing to the charge storage. In most other phases, the tunnel size is not sufficiently large to accommodate these cations. However, in foreign cation containing $\alpha-\mathrm{MnO}_{2}$ phases, the process of cation de-intercalation can be restricted due to the stabilizing effect of the tunnel cations. ${ }^{49}$ faradaic charge storage in these materials has been attributed largely to the surface adsorption of cations. Given the relatively high surface area of cryptomelane, it is to be expected that this would contribute significantly to the total charge storage.

Birnessite is another phase that is able to undergo cation intercalation due to the large interlayer spacing, which often results in high specific capacitances being recorded for this material. ${ }^{50,51}$ However, the specific capacitance recorded here is relatively low, which is 
(a) $\gamma-\mathrm{MnO}_{2}$

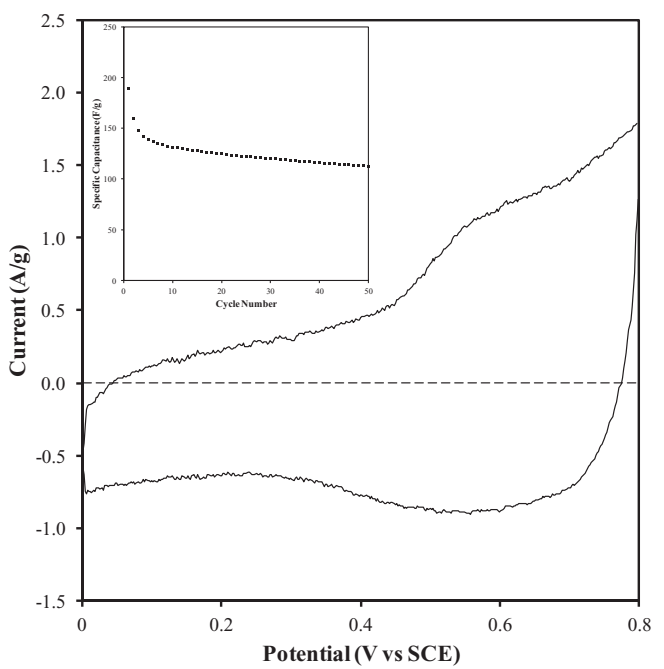

(c) Ramsdellite

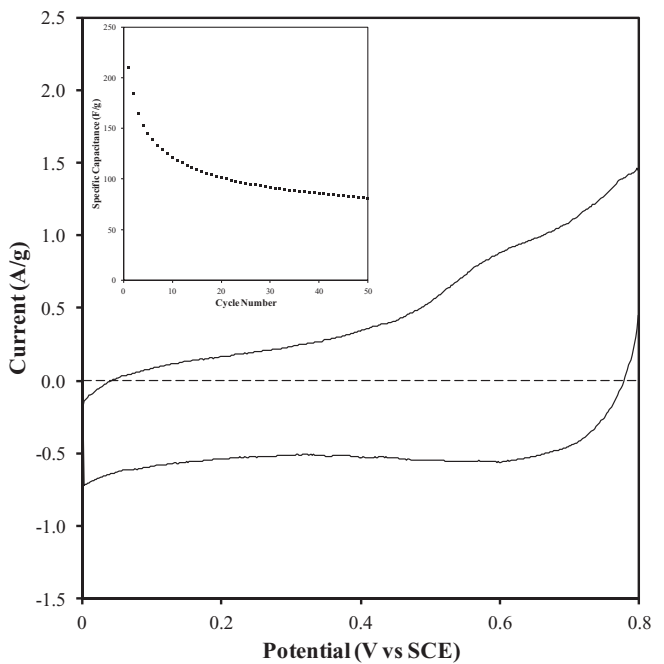

(e) Birnessite $\left(\delta-\mathrm{MnO}_{2}\right)$

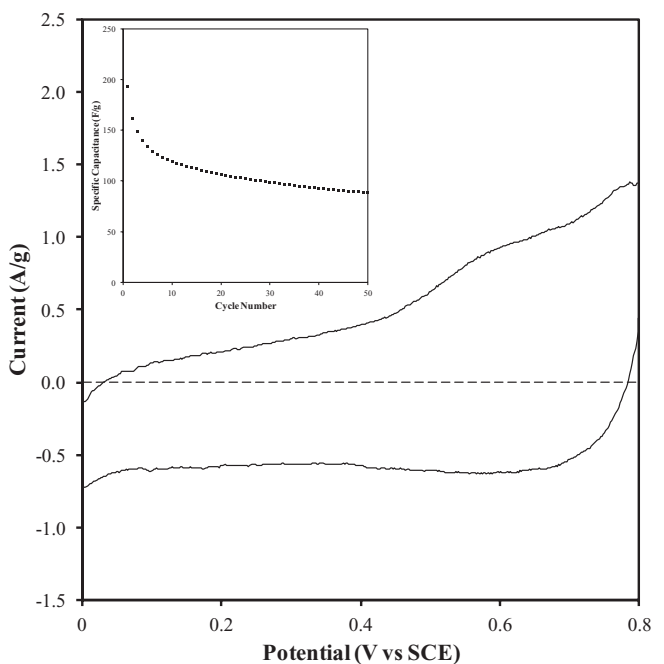

(b) Pyrolusite $\left(\beta-\mathrm{MnO}_{2}\right)$

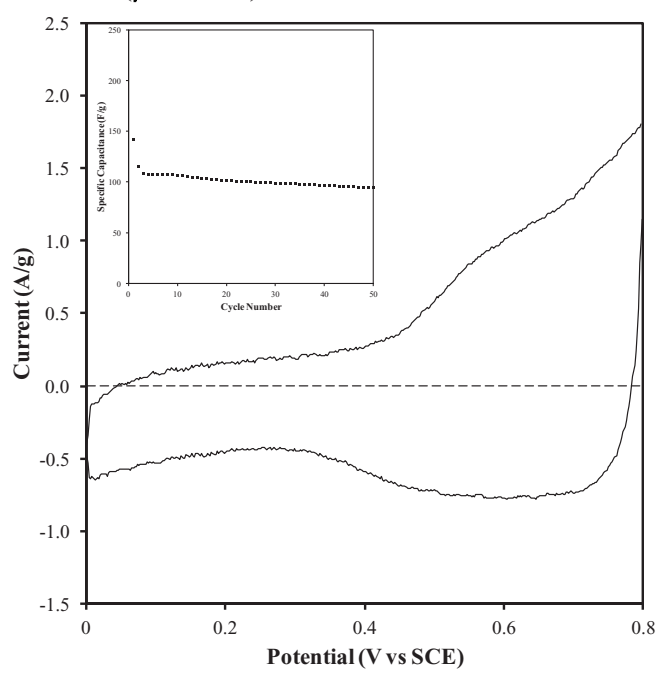

(d) Cryptomelane $\left(\alpha-\mathrm{MnO}_{2}\right)$

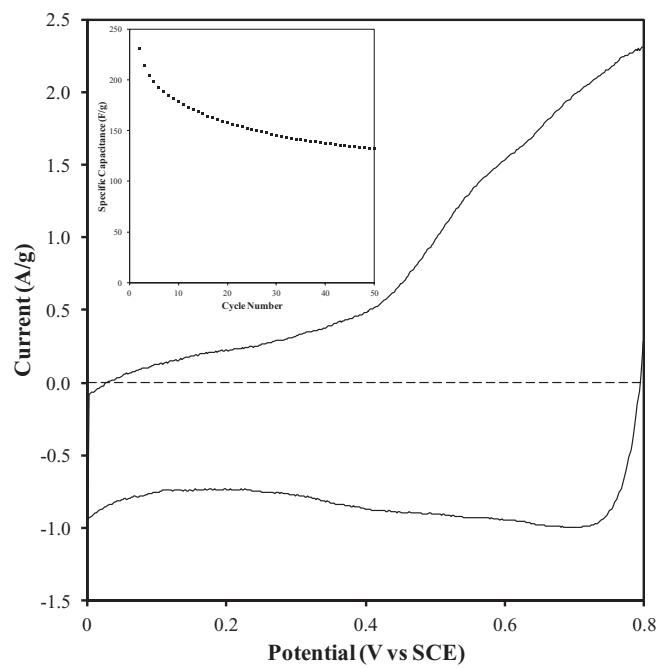

(f) $\lambda-\mathrm{MnO}_{2}$

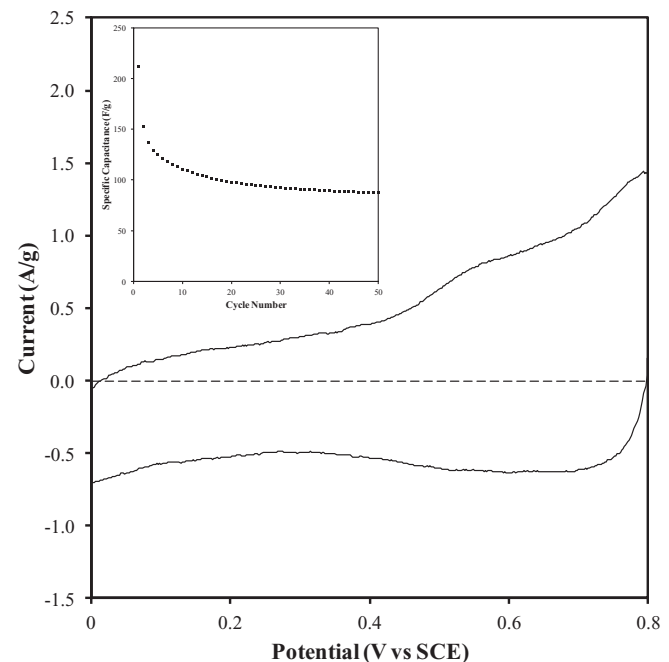

Figure 13. Cyclic voltammograms of different phases. 
unexpected due to its large surface area, but may also indicate that solid state charge transport is important, since the low diffusion coefficient correlates with poor electrochemical performance.

Generally, pyrolusite and ramsdellite exhibit fairly low specific capacitance compared to other phases. ${ }^{50,51}$ In pyrolusite, this is largely due to its low surface area and its observed low value for $A \sqrt{ } D$ value may also contribute to this. The data reported here suggests that the total energy storage capabilities of the materials are determined by a variety of processes including double-layer charge separation, cation adsorption onto the manganese dioxide surface, and proton (and cation) intercalation. While it is expected that diffusion would play an important role in the charge storage, is it also evident that it does not directly correlate with an increase in specific capacitance.

\section{Conclusions}

The effect of lattice structure on the rate of proton (and possibly other cation) diffusion in manganese dioxide was examined using a combination of electrochemical impedance spectroscopy (EIS) and step potential electrochemical spectroscopy (SPECS). Each phase was cycled in a step-wise fashion between $0.0-0.8 \mathrm{~V}$, and $\mathrm{A} \sqrt{ } \mathrm{D}$ values were obtained for each material in $25 \mathrm{mV}$ increments. Comparison of $A \sqrt{ } D$ values showed that all phases exhibited a decrease in $A \sqrt{ } D$ as the potential decreased from $0.8 \rightarrow 0.0 \mathrm{~V}$. This can be attributed to the expansion of the manganese dioxide lattice caused by the reduction of $\mathrm{Mn}^{4+}$ to $\mathrm{Mn}^{3+}$, and the corresponding intercalation of protons into the host structure. This increases the distance between adjacent sites, slowing the rate of proton diffusion through the structure. The reversal of this process upon charge causes the removal of protons, and hence increases the rate of diffusion.

Phases of manganese dioxide with higher surface areas $\left(\gamma-\mathrm{MnO}_{2}\right.$, ramsdellite and cryptomelane) exhibited hysteresis upon charging. This has been attributed to the slower kinetics of lattice contraction of surface domains in the material. Phases with lower surface areas (pyrolusite, $\lambda-\mathrm{MnO}_{2}$ ) did not exhibit this hysteresis, but instead showed relatively facile kinetics. This has been attributed to the greater proportion of bulk diffusion in low surface area materials. These lower surface area phases also exhibited some irreversibility in lattice expansion/contraction, indicated by the decrease in $A \sqrt{ } D$ values after cycling. Birnessite exhibited a significant phase change during discharge which is likely caused by the reduction of $\mathrm{MnO}_{2}$ to for $\mathrm{Mn}_{3} \mathrm{O}_{4}$.

Evaluation of the performance of each phase was conducted using cyclic voltammetry, where it was found that the specific capacitance did not directly correlate with $\mathrm{A} \sqrt{ } \mathrm{D}$, suggesting that material performance was a function of many variables, including solid state mass transport.

\section{Acknowledgments}

The authors acknowledge Chris Reilly for assisting with the synthesis of selected manganese dioxide phases. Jenny Zobec from the University of Newcastle Electron Microscope and X-ray facility is also acknowledged for her assistance in collecting the XRD patterns.

\section{References}

1. B. E. Conway, Electrochemical Supercapacitors. Scientific Fundamentals and Tech nological Applications, New York: Kluwer Academic/Plenum Publishers 2009.

2. J. W. Long et al., Langmuir, 15, 780 (1999).

3. Y.-Y. Liang, H. L. Li, and X.-G. Zhang, Journal of Power Sources, 173, 599 (2007).
4. H.-S. Nam et al, Electrochimica Acta, 56, 6459 (2011).

5. C. S. Johnson, Journal of Power Sources, 165, 559 (2007).

6. M. Sugantha, P. A. Ramakrishnan, and A. M. Hermann, International Journal of Hydrogen Energy, 28, 597 (2003).

7. D. Belanger, T. Brousse, and J. Long, Electrochemical Society Interface, Spring (2008) 49-52.

8. A. Kozawa and J. F. Yeager, J. Electrochem. Soc., 115, 1003 (1968).

9. A. Kozawa and R. A. Powers, J. Electrochem. Soc., 115, 122 (1968).

10. A. Kozawa and R. A. Powers, J. Electrochem. Soc. Jap. (Overseas Ed.), 37, 31 (1969).

11. A. Kozawa, J. Electrochem. Soc. Jap., Overseas Ed., 36, 196 (1968).

12. S. W. Donne, G. A. Lawrance, and D. A. J. Swinkels, J. Electrochem. Soc., 144, 2961 (1997).

13. S. W. Donne, G. A. Lawrance, and D. A. J. Swinkels, J. Electrochem. Soc., 144, 2954 (1997).

14. S. W. Donne, G. A. Lawrance, and D. A. J. Swinkels, J. Electrochem. Soc., 144, 2949 (1997).

15. V. M. Burns, R. G. Burns, and W. K. Zwicker, Proceedings of the Manganese Dioxide Symposium, 1 (1975).

16. R. G. Burns and V. M. Burns, Proceedings of the Manganese Dioxide Symposium, 1 (1975).

17. S. Turner and P. R. Buseck, Science, 203, 456 (1979).

18. J. C. Hunter, Journal of Solid State Chemistry, 39, 142 (1981).

19. W. M. Dose and S. W. Donne, Materials Science and Engineering: B, 176, 1169 (2011).

20. D. K. Walanda, G. A. Lawrance, and S. W. Donne, Journal of Solid State Chemistry, 182, 1336 (2009)

21. M. Pourbaix, Atlas of Electrochemical Equilibria in Aqueous Solution. 2nd ed., Houston: National Association of Corrosion Engineers 1974.

22. S. W. Donne, G. A. Lawrance, and D. A. J. Swinkels, Materials Research Bulletin, 30, 859 (1995).

23. P. H. Emmett and S. Brunauer, J. Am. Chem. Soc., 59, 1553 (1937).

24. K. J. Vetter and N. Jaeger, Electrochim. Acta, 11, 401 (1966).

25. A. M. Bystrom, Acta Chemica Scandinavica, 3, 163 (1949).

26. C. Fong, B. J. Kennedy, and M. M. Elcombe, Zeitschrift für Kristallographie - Crystalline Materials, 209, 941 (1994)

27. A. Bolzan et al., Australian Journal of Chemistry, 46, 939 (1993).

28. A.-C. Gaillot, B. Lanson, and V. A. Drits, Chemistry of Materials, 17, 2959 (2005).

29. J. E. Post, R. B. Von Dreele, and P. R. Buseck, Acta Crystallographica Section B, 38 1056 (1982).

30. Y. Chabre and J. Pannetier, Progress in Solid State Chemistry, 23, 1 (1995),

31. A. R. West, Solid State Chemistry and its Applications. 2nd ed., Oxford: John Wiley \& Sons 1991.

32. R. P. Williams, Characterisation and Production of High Performance Electrolytic Manganese Dioxide for use in Primary Alkaline Cells, in Chemistry, University of Newcastle: Callaghan 1996

33. A. J. Bard and L. R. Faulkner, Electrochemical Methods: Fundamentals and Applications. 2nd ed., New York John Wiley \& Sons, Inc 2001.

34. P. Ruetschi and R. Giovanoli, Journal of the Electrochemical Society, 135, 2663 (1988).

35. P. Ruetschi, Journal of the Electrochemical Society, 131, 2737 (1984)

36. P. Ruetschi, Journal of the Electrochemical Society, 135, 2657 (1988).

37. G. Aylward and T. Findlay, SI Chemical Data. 6th ed., Sydney: John Wiley \& Sons 2008.

38. A. Cormie et al., Electrochimica Acta, 55, 7470 (2010).

39. D. Qu, Electrochimica Acta, 48, 1675 (2003).

40. D. Qu, Electrochimica Acta, 49, 657 (2004).

41. P. Atkins and J. De Paula, Physical Chemistry: Oxford University Press 2006.

42. A. P. Malloy and S. W. Donne, Journal of Colloid and Interface Science, 320, 210 (2008).

43. J. Fitzpatrick and F. L. Tye, Journal of Applied Electrochemistry, 21, 130 (1991)

44. G. J. Browning and S. W. Donne, Journal of Applied Electrochemistry, 35, 871 (2005).

45. A. Cormie et al., Electrochimica Acta, 55, 7470 (2010).

46. A. Soffer and M. Folman, Journal of Electroanalytical Chemistry and Interfacial Electrochemistry, 38, 25 (1972).

47. J. Koresh and A. Soffer, Journal of Electroanalytical Chemistry and Interfacial Electrochemistry, 147, 223 (1983).

48. A. P. Malloy and S. W. Donne, Journal of the Electrochemical Society, 155, A817 (2008).

49. D. Zhai et al., Journal of Power Sources, 196, 7860 (2011).

50. S. Devaraj and N. Munichandraiah, Journal of Physical Chemistry, 112, 4406 (2008)

51. O. Ghodbane, J.-L. Pascal, and F. Favier, Applied Materials and Interfaces, 5, 1130 (2009). 